\title{
ON THE MORPHOLOGY AND LIFE HISTORY OF A MYXOSPORIDIAN, LEPTOTHECA OHLMACHERI, PARASITIC IN RANA CLAMITANS AND R. PIPIENS'.
}

\author{
By R. KUDO. \\ (University of Illinois, Urbana, Illinois, U.S.A.)
}

(With Plates XIII-XX, containing Figs. 1-111.)

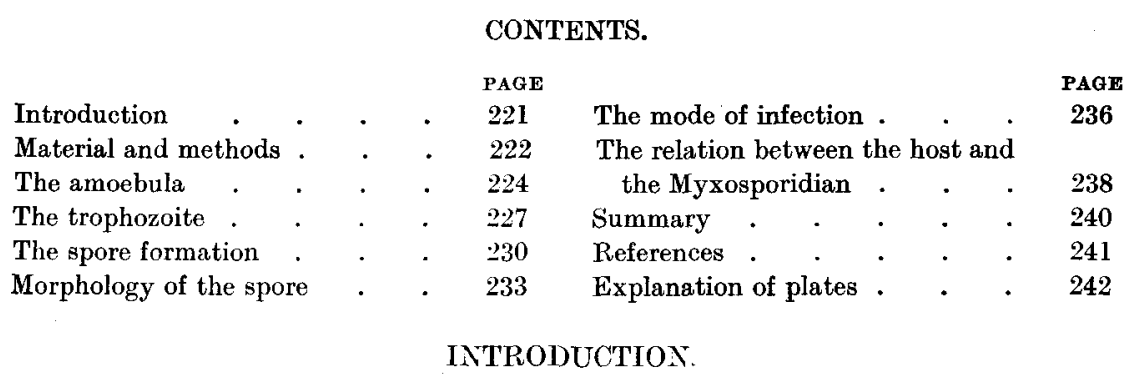

IN 1893 Ohlmacher observed spores of a Myxosporidian in the tubules of kidneys of Bufo lentiginosus. Whinery (1893) followed Ohlmacher with a further study on the Protozoan in the same host species. Both investigators obtained their material from De Kalb County, Illinois, U.S.A. They did not notice the vegetative form, and confined themselves solely to the descriptions of the spore. Gurley (1893), according to Whinery, named it Chloromyxum ohlmacheri after examining Ohlmacher's preparations. The same author (Gurley, 1894) summarized the results obtained by Ohlmacher and Whinery, and recorded the Myxosporidian as Chloromyxum (Sphaerospora) ohlmacheri. Thélohan (1895) gave a new specific name, Leptotheca ranae, to a Myxosporidian found in the kidneys of Rana esculenta and $R$. temporaria without giving any description or figure except its habitat ${ }^{2}$. Labbé (1899) placed the firstnamed species in the genus Leptotheca, and thought that it was identical with $L$. ranae.

The description and figures given by the first two American investigators show clearly that the shell-valves of the spore are finely striated, which fact had never been seen in any other spepies of the genus Leptotheca. Moreover, it is exceptional to find one that infects an amphibian host, because all

1 Contributions from the Zoological Laboratory of the University of Illinois, No. 201.

2 Thélohan does not mention the locality. Judging from the other species described in the paper, the host animals were most probably collected in France. 
the other species of the genus were found in marine fish. In the monograph on Myxosporidia, I (Kudo, 1920a) have, therefore, placed the species provisionally in the new genus Wardia on the basis of these peculiar characters which fit better to that genus than to Leptotheca.

Recently I have observed a Myxosporidian which, I believe, is identical with $L$. ohlmacheri, in the kidneys of $R$. clamitans and $R$. pipiens. The vegetative forms as well as spores at various stages of development were so abundant in numbers and the conditions were so favourable that $I$ have undertaken an extensive study on the morphology and the development of the organism. The study is without significance in view of the circumstance that none of the Myxosporidia parasitic in batrachian hosts which are listed in my monograph (Kudo, 1920a), has been examined in detail by the previous authors. It has been found that $L$. ohlmacheri possesses all the essential features characteristic of the genus Leptotheca, except that the spore membrane is striated and it occurs in amphibian hosts. The interesting character of the spore is that it contains two uninucleate sporoplasms which are independent and remain separated from each other. The development of the trophozoites, especially the process of gemmation occurring in the present species, stands sharply in contrast with those of other species observed recently by Georgévitch (1916, 1917 and 1917a), Davis (1916), Erdmann (1917) and Stempell (1919). Thus the study has revealed more or less interesting facts of general importance concerning this group of Protozoa.

The purpose of this paper is to present the observed facts, their interrelations, and the necessary reference to other disporous or mictosporous Myxosporidia. The discussion concerning spore formation in two vastly different groups of Myxosporidia, one infecting the tissues of the host and producing large cysts and the other living in the organ cavities of the host, was entirely omitted because of the recent appearance of papers (Erdmann, 1917, 1917a, and Stempell, 1919) and also of my belief that what is at present known of different species of Myxosporidia is yet too small for this purpose.

\section{MATERIAL AND METHODS.}

The Rana clamitans Latreille studied by me were collected in small creeks in Spring Valley, New York, during the summer of 1920. The R. pipiens Schreber were bought from a Chicago supply store and their locality is unknown, except that they were collected from various places in Iowa, Minnesota and Wisconsin. Further consideration upon the occurrence and the relation between the Myxosporidian and the host animals will be given later.

After studying the external characters, each frog was etherized and dissected. Smears of portions of the liver, spleen, blood, gall bladder, muscle, kidney, urinary bladder, reproductive organ, and wall of the digestive tract, were studied in physiological solution. The majority of $R$. clamitans have shown several protozoan blood parasites in the circulatory system. In no 
case, however, was the gall bladder found to harbour any Myxosporidia. The same has been true with other organs except the kidney. The observations on . fresh smears were further confirmed in stained smears and sections.

$L$. ohlmacheri was only found in the kidneys. Isolated spores were also found in the ureters, cloaca and urinary bladder of the host whose kidneys were heavily infected.

In order to get accurate knowledge of the organisms in the fresh state, large numbers of hanging drop preparations were made by mixing fresh spores of the Myxosporidian with the fluids taken from the stomach, small and large intestines and the urine of $R$. pipiens, physiological solution, and several diluted solutions of pepsin hydrochloric acid, lecithin and sodium glycocholate.

At the same time, many smears were made on slides from the kidneys, infected as well as normal. As my experience taught, in preparing the smears, it is very advantageous to have an extremely thin and a more or less thick region of film on each slide. In the former part, the number and division of the nuclei of trophozoites can be distinctly seen, while in the latter portion the general appearance, shape and size of the trophozoites can be clearly recognized.

The rest of the organ was fixed in toto, and sectioned. The serial sections varied from 2 to $5 \mu$ in thickness.

The fixatives employed are Schaudinn's fluid, Flemming's weak solution and Bouin's mixture, as used in my previous studies except the last named one (Kudo, 1916, 1917, 1920a and 1921). The first mentioned fixative proved to be most satisfactory. The methods of staining are the same as I have used before, i.e. Heidenhain's iron haemotxylin, Delafield's haematoxylin and Giemsa's stain. The advantage of mounting Giemsa-stained smears or sections in cedar oil for immersion, after dehydrating by acetone and acetone-xylol of different proportions, is noticeable compared with those mounted in the neutral Canada balsam or any other media. According to my experience, typical Giemsa staining in sections as well as smears, has been preserved perfectly in cedar oil for more than three years while those in neutral balsam have hardly lasted over six months.

As to the extrusion of the polar filament, I have recently discussed this elsewhere (Kudo, 1921a). It was easily induced by means of potassium hydrate or mechanical pressure. Moreover, a weak solution of sodium glycocholate gave good results in five to ten minutes in hanging drop preparations.

The gastric as well as intestinal fluids were collected by means of fine capillaries from the digestive tract after the frog was dissected. As the manipulation was done in November and December, the quantity of fluids obtained were usually so small as to suffice only for two or three preparations.

For artificial infection per os, small pieces of infected kidney or of a sterilized cork which was made porous previously by means of a needle, and immersed in an emulsion of fresh spores in physiological solution, were fed to the frog. 


\section{THE AMOEBULA.}

When fresh spores are brought into contact with the gastric fluid of the frog either in a hanging drop preparation or in the host's body, the following changes take place. The two sporoplasms increase gradually in size, and seem to fuse into a single mass along the surface of contact (Fig. 1). The amoebula shows very slow amoeboid movements, and appears to press the polar capsules against the anterior margin of the spore membrane (Figs. 1-3), which results in the extrusion of the polar filaments through the foramina. This condition was noticed only in gastric fluid or weak pepsin hydrochloric acid. In all other cases where the extrusion of polar filaments took place under the influence of reagents, such as potassium hydrate, lecithin or sodium glycocholate, the extrusion was more quickly brought about than in the case mentioned above, and no visible change occurred in the sporoplasms.

A similar movement of the amoebula inside the spore membrane prior to its emergence, seems to have been noticed by Auerbach (1910) in the case of Myxidium bergense.

After some time, the shell-valves become separated first at the anterior half (Figs. 4, 5) and then along the entire sutural plane (Figs. 6, 7). The amoebula was frequently seen making its way through this opening to the outside of the spore. The movements are very slow, yet can distinctly be followed in hanging drop preparations. When kept at $20^{\circ}$ to $25^{\circ} \mathrm{C}$., numerous amoebulae and empty spore membranes were noticed in the preparations after 6 to 24 hours. Similar changes to those stated above, were further noticed in spores treated with a mixture of gastric fluid and bile, and with the fluid taken from the duodenum. But no change was visible in the spores mixed with the fluids taken from the large intestine and with the urine. On the other hand, the action of weak pepsin hydrochloric acid upon the spores was similar to that of gastric fluid. The physiological solution and solutions of lecithin and sodium glycocholate did not cause any further change than the extrusion of the polar filaments.

The liberated amoebula moves about very slowly. Its nuclei cannot distinctly be made out in the fresh state, although not infrequently they were seen as faintly outlined bodies (Figs. 3,5). The cytoplasm does not show any distinct differentiation either in the fresh state or when stained. In the fresh state, it appears to be composed of homogeneous substance with three or more spherical granules of variable size. Figs. 8 and 11 show most probably one and the same amoebula. In this preparation, five spores were mixed with a drop of the gastric fluid after separating them from the others by means of serial dilution. The amoebula shown in Fig. 11 was moving about sluggishly after leaving the spore membrane. The cover glass was fixed and stained. Judging from its position upon the stained preparation, the amoebula shown in Fig. 8 is, in all probability, identical with that shown in Fig. 11. 
The nuclei in the amoebulae could only be studied in stained preparations. Staining shows that the nuclei of the two sporoplasms remain independent in the amoebula after the fusion of the cytoplasm, although they are found lying side by side (Figs. 4, 7).

Further observation on the amoebula could not be made either in hanging drop preparations owing to bacterial contamination, or in the animal body, although the sectioned stomach and intestine of four host animals which had been fed with the infected kidneys or cork, were carefully studied. In one amoebula shown in Fig. 9, which has been seen in a hanging drop preparation after 22 hours, the two nuclei were lying together, indicating that in the next stage a complete fusion of the two nuclei might occur.

Apparently, stages nearest to this were observed in the space between the glomerulus and Bowman's capsule of Malpighian bodies and in the uriniferous tubule below the Malpighian body of infected kidneys of $R$. pipiens. Quite frequently stages such as shown in Figs. 12-17 were observed in these parts of the kidney, although none were found to be in the epithelial cells of the tubule or in the surrounding connective tissue of the kidney. I consider the stage shown in Fig. 12 as that in which the nuclei of the amoebula are completing the fusion and those shown in Figs. 13-17 as those in which stages of schizogony of the young uninucleate amoebulae are represented. Since I have not seen the schizogony in the fresh state, I cannot state definitely that it occurs. Judging from the number of the parasites found, I am, however, inclined to think that schizogony also takes place beside the process of gemmation which occurs at a later stage of development.

The young uninucleate form is rounded with deeply staining reticulated cytoplasm and a large nucleus. At first the nucleus seems to be rich in the nuclear sap and to be surrounded by a somewhat indistinct membrane. The chromatic substance is collected in one place in the form of a karyosome (Figs. 17, 18). Owing to the variable shapes it assumes (Figs. 18, 19), the young parasites seem to undergo amoeboid movements. The cytoplasm is uniformly reticulated, often showing more or less large vacuoles (Fig. 19). As the body grows, the nucleus undergoes changes. The nuclear membrane becomes now distinctly visible and the karyosome more compact. The achromatic network, on which chromatin granules are scattered, becomes clearly observable (Figs. $19,20)$.

The germination of the myxosporidian spores has undoubtedly been one of the important objects of study to investigators. I shall quote some records on the subject in species of similar habitat. Auerbach (1910) figured the separation of the shell-valves of a spore of Myxidium bergense which had been introduced into the intestine of one of its hosts, Gadus virens, and further stated that when spores were taken from the stomach and mixed with a drop of the host's bile on a slide, the polar filaments became extruded, and that "nach 20 Min. bis $\frac{1}{2}$ Stunde kann man auch leere Schalen finden, ein Zeichen, dass die Amoeboidkeime ausgekrochen sind." Davis (1916) observed that 
the shell-valves of the spores of Sinuolinea dimorpha became separated from each other along the sutural line, and that when spores were subjected to the action of the fluid taken from the pyloric caeca of the host fish, the amoebulae emerged "in five to fifteen minutes" through the openings. Georgévitch (1917a) stated that he observed a similar separation of valves in the spore of Ceratomyxa coris. On the other hand, Erdmann (1912) describes an apparently abnormal occurrence in a spore of Chloromyxum leydigi. By adding to the spores placed on a slide first gastric fluid and then the bile of the host fish, she noticed the liberated binucleate amoebulae in the mixture, and stated that "die Sporenwände reissen (Fig. 8) nicht in der Nahtlinie, sondern in einer um $90^{\circ}$ zu ihr geneigten Ebene." The mentioned figure does not contain any of the four polar capsules, and may be interpreted as a case of separation of the valves along the sutural plane.

Concerning the nuclear changes prior to and after the emergence of the amoebula, there are two views. According to Auerbach (1910, view 1) and Stempell (1919), the two nuclei of the sporoplasm fuse into one prior to the emergence of the amoebula. According to Auerbach (1910, view 2), Erdmann (1912 and 1917) and Georgévitch (1917 and 1917a), however, the fusion of the two nuclei takes place after the emergence of the amoebula. The nuclear changes in the present species agree with the latter view.

Whether or not there is an intracellular stage in a Myxosporidian, the trophozoites of which live in the organ cavity of the host animal, has been the subject of study of several writers. The fact that Myxosporidia living in organ cavities of the host, may invade the tissues under certain conditions, was demonstrated recently by two examples. Debaisieux (1918) noted that Myxidium lieberkühni Bütschli which is a well-known parasite in the urinary bladder of Lucius lucius, invades not only the lumina of the ureters and uriniferous tubules, but also the glomerulus of the Malpighian body of the kidney of the host and develops into large cysts. I have also seen a similar case in Mitraspora elongata parasitic in the kidney of Lepomis cyanellus (Kudo, 1920a). Several investigators suggested the possible occurrence of an early intracellular stage in the Myxosporidia occurring in the organ cavities of the host animals.

Not in many cases was this stage actually recognized. Regarding the young intracellular stages of Chloromyxum protei parasitic in the uriniferous tubule of Proteus anguinus, Joseph (1907) makes the following statement: "Ich fand ausgesprochene Jugendstadien anfangs regelmässig nur in den Zellen der flimmernden Anfangsteile der Nierenkanälchen, also in den Nephrostomialund den Nebenkanälchen im Sinne der Nomenklatur von Felix." Auerbach (1910) observed in $M$. bergense and Zschokkella hildae that the uninucleate amoebula enters into the epithelial cell of the gall bladder or of the proximal portion of the gall duct of the host fish, although its significance was unknown.

Examination of a large number of sections of kidneys infected by Leptotheca 
ohlmacheri to a varying degree, has failed to reveal any evidence which might prove the occurrence of an intracellular stage.

\section{THE TROPHOZOITE.}

The nucleus in the young uninucleate form undergoes division. Its karyosome becomes larger and less dense (Fig. 21). It divides into two equal parts. The daughter karyosomes move toward the opposite ends of the nucleus. Frequently a deeply staining chromatic strand exists between them for some time (Fig. 23). At first, the reticulated achromatic network does not show much change, but later it becomes more densely accumulated at the equatorial plane together with the chromatin granules (Fig. 23). The nucleus finally divides into two along this plane and the two daughter nuclei may remain attached to each other (Fig. 24). At the end of the division, the two nuclei seem to be similar in structure. Changes in appearance, however, take place soon afterward. One nucleus $(a)$ shows a large karyosome which is usually attached to the nuclear membrane and a very fine achromatic network, thus resembling in appearance that of the uninucleate form before division. The other nucleus $(b)$, however, shows a decrease in the size of the karyosome compared with the former and chromatin granules become scattered over the coarse achromatic network (Fig. 25). The former (a), as its later history indicates, is the vegetative nucleus, the latter $(b)$ is generative. The two nuclei show a striking difference especially when stained with Giemsa's solution: the vegetative nucleus assumes a light pink colour with a light bluish karyosome, while the chromatin granules scattered on the achromatic network and the karyosome of the generative nucleus stain a deep red.

The generative nucleus undergoes further division without any resting period. The division takes place in a similar manner as was stated above for the first division, preceded by the division of the karyosome and chromatic network (Figs. 26-28). Fig. 29 shows two views of a trophozoite in which the two daughter generative nuclei have just completed the division. In wellmade smears, the distance between these two nuclei is much smaller than that between the vegetative nucleus and either one of them. Figs. 30, 31 and $41-43$ show typical trinucleate trophozoites.

In all known cases, the earliest phase of the trophic life is the uninucleate form. Concerning the formation of the binucleate form, there are two views. According to Auerbach (1910) in the development of $M$. bergense, two uninucleate forms come in contact and one of the copulants casts off a part of the nuclear substance, thus forming a binucleate form with nuclei dissimilar in size. On the other hand, Davis (1916), Georgévitch (1917a), Erdmann (1917) and others, maintain that the nucleus of the uninucleate form produces those of the binucleate form by division. Of these latter authors, Georgévitch thinks that the division is unequal and forms a smaller generative and a larger vegetative nucleus. Davis, however, observed equal division so that the daughter nuclei were of "equal size and similar appearance." In Leptotheca 
ohlmacheri, the two nuclei, as before stated, are usually of similar size, but assume soon afterward strikingly different aspects.

Formation of trinucleate trophozoites similar to that described above, was observed in Sinuolinea dimorpha (Davis, 1916), and Ceratomyxa coris (Georgévitch, 1917a). Stempell (1919), however, believes that the trinucleate trophozoite of Ceratomyxa (Leptotheca) coris is formed directly from a uninucleate form by a heteropolar nuclear division. This controversy, arising from the observations of Georgévitch and Stempell on apparently one and the same species, is beyond my understanding. But in L. ohlmacheri, I have not seen a single instance which might suggest the occurrence of the process described by Stempell in the above-mentioned species.

Concerning the relative number of trophozoites with one, two and three nuclei respectively in the infected host organs, Georgévitch (1917a) and Stempell (1919) noticed that the number of trinucleate trophozoites of Ceratomyxa coris, were much greater than any other stages. In this connection, Georgévitch states that "ce stade assez fréquent dans nos préparations indique un stade de repos." On the other hand, Stempell attributes the reason to the above quoted heteropolar division of the nucleus of the uninucleate form.

In $L$. ohlmacheri, the number of trinucleate trophozoites is far greater than that of uninucleate or binucleate forms. In my opinion, this is due to the following two reasons. In the first place, this stage is most probably one of growth. As was noted in every one of the infected kidneys, the body of the trophozoites at this stage varies greatly in size which is reasonably explained by regarding it as a growth stage. Secondly, as will be stated later, young trinucleate trophozoites are constantly produced by the process of gemmation in the later stage.

The karyosome in the vegetative nucleus of a trinucleate trophozoite is frequently divided into two (Fig. 33), one of which remains in the vegetative nucleus. This gives rise to another generative nucleus (Fig. 34) which divides into two (Figs. 35, 36). At the same time, these become surrounded by more deeply staining cytoplasm, and separated from the main part of the cytoplasm by a clear space. One of the nuclei, becomes the vegetative nucleus, while the other divides once more, thus forming a trinucleate form, with one vegetative and two generative nuclei. The trinucleate body is extruded from the mother trophozoite. I have repeatedly seen gemmation in hanging drop preparations, the time needed for the completion of the process varying from 30 minutes to 3 hours at $20^{\circ}$ to $25^{\circ} \mathrm{C}$. The extrusion may in some cases be much delayed (Figs. 39, 40). The liberated trinucleate stage is essentially the same in the nature of the nucleus with that of the mother trophozoite, mainly differing in size of the body (Figs. 37-40). The body of the gemma now grows and repeats the same process. One gemma is formed in a trophozoite at one time. Whether or not one individual undergoes repeated gemmation cannot definitely be stated. But judging from the large number of the trinucleate stage present in every case, I am inclined to think 
that the gemmae are formed repeatedly one after another in one individual. Frequently one of the two generative nuclei, instead of developing into a spore, forms a gemma (Fig. 38). This appears to occur near the end of repeated gemmation. In such cases, after the liberation of the gemma, the mother trophozoite contains one spore and the vegetative nucleus (Figs. 38, 86).

Davis (1916 and 1917) observed the formation of several gemmules in the polysporous trophozoites of Sinuolinea dimorpha and S. capsularis. In regard to the gemmation of the first named species, Davis writes as follows:

Occasionally a degenerative cell is seen, in which division of the nucleus is not followed by a corresponding division of the cytoplasm. Successive nuclear divisions follow in rapid succession until eight nuclei are formed, all enclosed in a common cytoplasmic mass (Figs. 67 to 71 ). Meanwhile, the entire structure increases considerably in size, forming a very characteristic rounded body, sharply marked off from the surrounding endoplasm (Figs. 59, 60, 69 and 70). These bodies are probably homologous with the pansporoblasts but have a very different history from the ordinary structures of that name. They are, in reality, similar to the gemmules formed by many species of Protozoa.

Although many other authors record the occurrence of plasmotomy in various species of Myxosporidia (Kudo, 1920a), the discussion of which is beyond the scope of the present paper, the above quoted observation of Davis deserves consideration here. Yet the two types of gemmation differ in several respects. In the first place, the character of the sporulation in the trophozoites differs in each case-the one is polysporous (S. dimorpha) and the other disporous (L.ohlmacheri). In the disporous form of $S$. dimorpha, Davis did not see the process of gemmation. Secondly, the nature of the nuclei in the gemma and the number of gemmae formed at one time differ in the two forms. In this connection, it may be interesting to note that although the authors did interpret their observations in different ways, a study of their figures reveals cases in which gemmation similar to that of the present species may occur. For examples, the trophozoite of Ceratomyxa (Leptotheca) coris which Stempell (1919) showed in his Figs. 54 and 116, contains a sharply outlined body which the said author interpreted as "Vierergruppe." One may say, especially after studying Fig. 116, that this appears to be a trinucleate gemma similar to that of the present species, since the nucleus located near the lower edge of the body seems to be that of a schizont of Nosema marionis which had been included in the cytoplasm of the gemma. Again, the disporous trophozoites of $S$. dimorpha shown by Davis (1916) in his Figs. 29 and 31, may represent stages of a gemmation similar to the above. Comparative study of the three species will probably lead to interesting results.

This process of gemmation is of great significance to the parasite. As the Myxosporidian lives in the lumina of the uriniferous tubules of the host, possibly absorbing the waste matter secreted by the host cells, it is advantageous that its body should remain small so as not to disturb the function of the host organ. By schizogony and gemmation, the number of the parasites will be greatly increased thereby maintaining the species 
without greatly impeding the function of the host organ. Thus the process of gemmation may be interpreted as an adaptation of the parasite to its habitat.

The cytoplasm of the young trophozoite is poorly differentiated. Up to the trinucleate stage, the ectoplasm is hardly distinguishable from the finely reticulated endoplasm. When fixed, the differentiation becomes less visible than in the fresh state. Although there is no difficulty in distinguishing young trophozoites from leucocytes in stained preparations (Figs. 109-111), it is frequently a hard task to separate them in hanging drop preparations, as both form pseudopodia of similar shape, and the nucleus is usually invisible (Figs. 105-108).

\section{THE SPORE FORMATION ${ }^{1}$.}

The trinucleate trophozoite, as was stated before, contains the vegetative nucleus and two generative nuclei, each of which becomes a spore by future development (Figs. 41-43). Rarely the vegetative nucleus is seen dividing at later stages (Fig. 48). This division produces two daughter nuclei, one of which remains as the vegetative nucleus of the trophozoite, while the other produces a gemma (Figs. 39, 48, 52). A single vegetative nucleus is always observable in the trophozoites at later stages of development (Figs. 49-60, $71,81-86)$.

The division of the generative nuclei is similar to that described before in the case of the primitive generative nucleus. It is preceded by the elongation of the nucleus in the shape of a spindle and the division of the karyosome. The chromatin granules scattered on the network become separated into two groups, each condensing near the end of the spindle (Fig. 44). After the complete separation of the karyosomes, the separated chromatin granules surround each of the former (Figs. 45, 48, 49) and the daughter nuclei finally result.

Since the divisions of the two generative nuclei may or may not take place simultaneously, there are seen trophozoites, the number of whose nuclei vary from five to thirteen (Figs. 45-54). I shall describe the divisions of one of the generative nuclei, as those of the other are essentially the same.

The generative nucleus (Figs. 41-43) divides once and forms two daughter nuclei, one for the spore membrane and the other for the sporoplasms and the polar capsules (Figs. 45-47). The former divides again forming two nuclei,

1 Young as well as sporulating trophozoites were abundantly present in the tubules of the kidneys of every infected host animal. At the time when Ohlmacher and Whinery studied the Myxosporidian, very little was known regarding the Myxosporidia possessing in their life cycle small trophozoites and living in the organ cavities of the host. On the other hand, Myxosporidia that produced large cysts in the host tissue or that developed into large vegetative forms such as Sphaeromyxa (Cystodiscus) immersa, were comparatively well known. It seems probable that these authors searched for large cysts or trophozoites, and overlooked the relatively small vegetative forms as stated here. In this connection, Ohlmacher states that " $i t$ is probable that, in this case, the parasite did not reach its adult condition in its batrachian host; but here only passed one stage of its evolution; that is, the spore stage." The inaccuracy of this statement is obvious. 
each becoming the nucleus of the valve cell, and occupies the outermost position in the group (Figs. 38, 50-55). The latter also divides into two nuclei, each one being destined for the nuclei of sporoplasms and polar capsules respectively (Figs. 50, 51). The third division follows quickly. Finally we have two nuclei for the capsulogenous cells and two for sporoplasms, which become arranged in a space between valve cells (Figs. 53-55). These last mentioned two divisions seem to take place in quick succession so that before the complete separation of the daughter halves, the next division becomes partly completed. The result is that stages such as are shown in Fig. 38 (in which the two sporoplasms and the two capsulogenous cells are still connected at one point) were seen quite frequently. This circumstance, I believe, is well fitted for the purpose of development of normal spores, allowing time for the valve cells to surround and include the other four cells inside the mass. The nuclear changes stated above are always seen under normal conditions.

Various abnormalities are, however, frequently noted. In the first place, as already stated, one of the generative nuclei in the trinucleate stage, may not form a spore at all, but it may produce a gemma (Fig. 38), or it may not divide whilst the sister nucleus divides repeatedly and develops into a spore (Fig. 85). In this case, the trophozoite is monosporous. Again one of the valve cells and one of the capsulogenous cells, may divide once more, in which case a spore with three shell-valves and as many polar capsules, is produced (Figs. 84, 101).

Since the trinucleate trophozoites and their nuclei differ more or less greatly in size, the later stages show similar difference in size. But, since the generative nuclei in one and the same trophozoite appear to undergo divisions with more or less accurate mathematical ratio, the daughter nuclei of corresponding stages in each of the developing stages are similar in size to each other. Indeed in the great majority of cases two spores developed in one trophozoite are of approximately the same dimensions (Figs. 53-60, 81-83, 87-89). Two trophozoites shown in Figs. 82 and 83 were seen lying side by side in a smear. While the size of the spores differs considerably in these trophozoites, the two daughter spores in each trophozoite are of similar size.

The valve cells which are usually located laterally in relation to the other four cells (Fig. 53), become elongated, and surround the other four cells completely in the form of a deeply staining narrow band (Figs. 54, 55, 57-74). During the formation, the nuclear substances break up into small fragments and transform with the cytoplasm of the cell into a typical substance, the nature of which I have studied elsewhere (Kudo, 192la). In the formation of the spore membrane of $L$. ohlmacheri, there is no indication that glycogen constitutes a part of the spore membrane as was maintained by Erdmann (1917) in the case of Chloromyxum leydigi.

As to the formation of the polar capsules and the polar filaments, there have been large numbers of contributions by authors such as Thélohan (1895), Doflein (1898), Auerbach (1910), Awerinzew (1909), Davis (1916), George- 
vitch (1917a) and Erdmann (1917) since the first work by Bütschli (1881) on the subject. Of the recent workers, Erdmann (1917) states that the polar filaments of C. leydigi are composed of glycogen and plastin. That this was not the case in the several species of Myxosporidia which I had studied, was reported in one of my papers (Kudo, 1921a). The first indication of the formation of the structure under consideration, is recognized when a deeply staining club-shaped mass (Fig. 53) appears in the capsulogenous cell. The nature of this substance is not clear, but it is certainly not glycogen or a similar substance. On the other hand, since the nucleus is not only closely applied to the said mass, but directly connected with it, it is most probably composed of chromatin substance and nuclear sap and of the transformed cytoplasm of the cell. The mass grows larger; one end becomes much larger than the other (Fig. 53). At the same time, the cytoplasm shrinks and a vacuole is formed in which the deeply staining substances accumulate. As the mass becomes still larger, it bends to one side, assuming a retort shape, the nucleus feeding its chromatin granules constantly into the growing mass (Figs. 61-63, $65)$. The fine extremity of the mass becomes coiled around the other rounded end (Figs. 60, 66-69). When the spiral of the filament is completed, there differentiates from the outer region of the mass a sac-like structure which surrounds the polar filament (Figs. 60,66-69). This is the polar capsule. Although its length is a moderate one compared with that of several other species I have studied (Kudo, 1917, 1918 and 1920a) the polar filament is comparatively thick. The nucleus of the capsulogenous cell seems, therefore, to be used up entirely in most cases for the formation of the polar capsule and polar filament. In mature spores, no remnant of the nucleus of the capsulogenous cell, is usually seen (Figs. 78, 87-90, 94, 96-99, 101-103), though occasionally this is not the case (Fig. 81).

During these changes, the sporoplasms, each containing a single nucleus, remain separated from each other and without any noticeable change (Figs. 53-77, $81,87-90,94,96,97)$. This is certainly a peculiar feature of the species. Even in the completely developed spores, the two sporoplasms remain independent.

During the formation of spores, the vegetative nucleus of the trophozoite remains unchanged in its external appearance. It is, in almost all cases, found on one side of the body and usually between the developing spores (Figs. 53-60, 81-85, 89). Contrary to the observations made by other authors on several species of Myxosporidia, the vegetative nucleus of the trophozoite of $L$. ohlmacheri, instead of undergoing degeneration, grows and increases in size as the trophozoite grows and the spore formation proceeds (Figs. 52, $60,81-83)$. This demonstrates that it controls the vital trophic function of the vegetative form during the entire period of its existence. A similar state has been observed in S. dimorpha (after Davis) and C. coris (after Stempell). The necessity of having a functioning vegetative nucleus is also well understood, if one considers the fact that the fully grown trophozoite containing two mature spores undergoes active formation of pseudopodia (Fig. 89). 
There is a little difficulty in distinguishing young stages from the leucocytes in the fresh state. The larger trophozoites can easily be distinguished from any other objects found in the preparations even in unstained conditions. An unmistakable character of a living trophozoite is the presence of four polar capsules under formation, even when no nucleus can be detected in the body. The cytoplasm of larger trophozoites is clearly differentiated into two parts, the ectoplasm and the endoplasm. When a drop of emulsion of an infected kidney in physiological solution is made into a hanging drop preparation, large trophozoites will be seen to produce active pseudopodia from localized parts or from the entire surface of the body (Fig. 89). The pseudopodia are those that have commonly been seen in several species of the family Ceratomyxidae. They are of a long conical form and end in points. When the trophozoites are kept in the preparation for from 3 to 8 hours, the pseudopodia are withdrawn, and lobose ones may be seen sluggishly formed in their place. Frequently even in freshly-made emulsion, rounded trophozoites without any pseudopodia are encountered (Fig. 87). The ectoplasm is especially visible at the place where the pseudopodia are formed, they are entirely composed of the ectoplasm. In rounded forms, the differentiation is poor (Fig. 87) and the ectoplasm forms a rather tough homogeneous hyaline layer around the body. The endoplasm is finely reticulated, and in places greatly vacuolated. The trophozoite contains spherical bodies of variable size (Figs. 87-89), which are of fatty nature.

\section{MORPHOLOGY OF THE SPORE.}

The mature spores are, as a rule, rounded elliptic with the longest axis standing at right angles to the sutural plane ${ }^{1}$ (Figs. 87-98). The form varies, however, considerably. Frequently the breadth is reduced to that of the sutural diameter so that the spore approaches a sphere in the front view. In all cases, the anterior tip is more or less drawn out due to the thickening of the spore membrane at that point. The posterior margin is always rounded except the sutural ridge which stands out prominently at its middle portion. In the anterior end view, the spore is elliptic (Fig. 87), while in profile, it is almost circular with a slightly pointed anterior end (Fig. 99). The spore membrane is moderately thick, and is composed of two valves of usually equal size and form. The anterior tip of each valve is thickened and forms a small rounded highly refractive body (Figs. 87, 92, 96-98). The sutural ridge is straight and prominent. The spore membrane is marked with numerous striae, the pattern of which can be easily studied on an empty spore. Although the striation is apparently irregular in many spores, the following pattern is recognized in most cases: A few striae, three to seven, run parallel to the sutural line, while all the others form somewhat similar angles with the sutural line (Figs. 91, 93, 95). Frequently the latter striae on each valve centre

1 The definitions of the terms used here, are given in one of my papers (Kudo, 1920a). 
in two points near the ridge and midway between the anterior and posterior ends. Along the lateral surface, the majority of the striae run parallel to each other, although not infrequently the regularity is broken by short longitudinal striae near the posterior end (Fig. 100). These striae appear as fine spinous projections around the entire margin of the spore in its optical section (Figs. 90, $92,94)$. The number of striae on each valve varies from 25 to 35 .

Each spore contains two polar capsules in its anterior half. They are spherical in shape, and are in most cases of equal dimensions in one spore. The wall is very thin and the coiled polar filament can distinctly be seen in vivo. The polar filament is spirally coiled usually from four to five times, though rarely up to eight times. It always leaves a considerable space between it and the wall of the polar capsule. The coiled condition of the filament gives further evidence in support of my observations made on other species (Kudo, 1920a). There is no central axial portion around which the filament might be coiled as was supposed by some authors such as Awerinzew (1909) and Stempell (1919) on the same structure in other species.

The polar filament penetrates through the capsule at its anterior part, and is connected with its foramen at the anterior tip of the spore membrane and outside of the thickened portion (Figs. $73,75,88,96$ ). The continuity of the polar filament with the capsule and further with the foramen in the spore membrane, has long been known and many authors referred to the structure mainly showing the relation in the front view of the spore as shown in my. Figs. 73, 75 and 88. Joseph (1907) saw the foramina of spores of Chloromyxum protei, and gives two excellent microphotographs.

In section preparations I have frequently noticed such parts of spores as are shown in Figs. 79 and 80 . These are tangential sections of the spore membrane through the anterior tip. That this is the case is easily seen by the presence of a more deeply stained area on both sides of the sutural line, which corresponds to the anterior thickening in the shell-valves, by the direction of the striae, and further by tracing the rest of the spores in the adjacent sections. These foramina are very small openings situated on either side of the sutural plane and almost equidistant to it.

The extrusion of the polar filaments was easily induced (see p. 223).

The most striking feature of the spore which commands especial attention is its sporoplasms. Ohlmacher who only studied stained sections made from the infected kidneys of Bufo lentiginosus which were fixed with absolute alcohol, stated that "in the case in which this substance (protoplasmic mass) was less in amount, a well defined segmentation was frequently noted; the line of division extending through the middle of the mass, each half of the divided mass enveloping a pole corpuscle (polar capsule) in the form of a well defined crescent." I have paid little attention to this statement because the kidneys were fixed with absolute alcohol which might have caused the "segmentation" in Ohlmacher's preparations, and also because Whinery, studying fresh spores under Ohlmacher's direction, did not emphasize this appearance. 
In the spores of several species of Myxosporidia, which I have studied up to the present (Kudo, 1920a, 1921b), I have always seen a single binucleate or occasionally uninucleate sporoplasm in each individual.

On examining the spores of $L$. ohlmacheri, I was surprised to find that each spore contained always two sporoplasms. Even in a fresh condition, one can distinctly recognize two sporoplasms in every spore, young as well as mature, clearly separated from each other (Figs. 55, 87, 90, 94, 96, 97). They are rounded and distinctly contoured. They may be of unequal form in one spore, yet their volume appears to be approximately the same. In some spores, they may be small and remain as rounded masses in the posterior portion of the spore (Figs. 87, 97), while in others they may be comparatively large and occupy more than half the cavity, extending anteriorly around the polar capsules (Figs. 88, 90). In the fresh state, the sporoplasms are of uniformly homogeneous hyaline cytoplasm destitute of the usual fine granulation found in the sporoplasm of spores of other species. They, however, contain small refractive globules of variable size and number (usually from three to five) which are of fatty nature. The nucleus can ordinarily not be observed in the unstained state. Another strange feature of the sporoplasms is their strong affinity for nuclear stains. When the spores in smears are fixed and stained by any of the stains used, the sporoplasms often withstand the decoloration, and remain deeply stained, in which case the detection of their nuclei is impossible.

As far as I am aware, Erdmann (1917) is the only investigator who, dealing with Chloromyxum leydigi, has concluded that "die junge einkernige Chloromyxidie ist aus einer Anlage entstanden, die zwei Zellen und zwei Kerne in der Sporenhülle hatte." She has figured three stained spores of the species, which, however, do not illustrate the statement distinctly. Aside from Erdmann's observation Thélohan (1895) mentioned that in the spore of Ceratomyxa sphaerulosa the "protoplasm n'occupant qu'une des valves, dans l'autre valve, on voit d'ordinaire de petit amas d'une substance très pâle(x)." Whether this substance represented the second sporoplasm or not remains unsettled.

Although the size of two spores formed in one trophozoite is usually similar, spores from different individuals may vary considerably. Measurements of a large number of spores gave the following average dimensions: Fresh spores: sutural diameter and thickness $9 \cdot 5-12 \mu$, breadth $13-14.5 \mu$, diameter of polar capsules $3-4 \cdot 5 \mu$, length of extruded polar filaments $42-62 \mu$. Stained spores: sutural diameter and thickness $8-10 \mu$, breadth $9-12 \mu$, diameter of polar capsules $3-4 \mu$.

These dimensions differ greatly from those of Ohlmacher's form, since this author records the sutural diameter and breadth of spores in sectioned preparations as $6 \mu$ and $8 \mu$ respectively. It is, however, understood that the section preparations always give much smaller dimensions of spores or trophozoites compared with those of stained smears or particularly of fresh 
preparations (Kudo, 1922). I am inclined to think that the spores measured by Ohlmacher underwent a strong shrinkage. Yet it is difficult to understand that Whinery who, notwithstanding his having studied fresh spores, records exactly the same dimensions as Ohlmacher, although he remarks that the size varied to some extent.

In view of the size of the spores, and their general appearance, striae and occurrence, etc., I am unable to regard the form I have herein described as a new species.

As is the case with every species of Myxosporidia, malformation of spores is frequently noticed. Two or three spores, each with three shell-valves and as many polar capsules, are always seen in every smear preparation. Extremely small spores are also not infrequently noticed (Figs. 83, 98).

\section{THE MODE OF INFECTION.}

Regarding the mode of infection with $L$. ohlmacheri, Ohlmacher states: "as to the origin of the myxosporidian infection, we can only conjecture that it must have occurred by way of the cloaca to the bladder, eventually lodging in the kidneys." This amounts to a mere supposition, and consequently has received little attention from recent investigators.

Joseph (1907), working on Chloromyxum protei, parasitic in the lumen and epithelium of the uriniferous tubule of the kidney of Proteus anguinus, came to the following conclusion:

Frägt man sich nach dem Infektionsmodus, so ist es nach den Befunden an anderen Myxosporidien und den lokalen physiologischen Verhältnissen in der Niere am wenigsten wahrscheinlich, dass ein befallenes Tier mit den in ihm entstandenen Sporen sich selbst von neuen infiziert, das Naheliegendste ist doch sicher die Annahme einer Übertragung auf ein anderes Individuum auf dem Wege des Wassers. Der Umstand, dass die jüngsten Infektionsstadien sich meist in den Harnkanälchenabschnitten fanden, die unmittelbar mit dem Cölom in Verbindung stehen, liess die Vermutung in mir aufkommen, ob nicht dies der Weg ist, den die Keime, die Darmwand durchsetzend, nehmen und veranlasste meine Fütterungs- und peritonealen Infektionsversuche.

In the course of his study on $S$. dimorpha, parasitic in the urinary bladder and Wolffian ducts of $C$. regalis, Davis (1916) noticed that "spores when placed on the slide without previous exposure to sea water, and mixed with a drop of fluid from the pyloric caeca of the host, usually germinated within five to fifteen minutes," and concluded that "it appears probable, therefore, that the free spores, when taken into the intestine of the host, germinate, and the sporozoites, as free amoebulae, actively make their way into the urinary bladder."

According to the results obtained by Auerbach and Erdmann, the spores of $\boldsymbol{M}$. bergense, $\boldsymbol{Z}$. hildae or $C$. leydigi, germinate in the duodenum of the new host fish. The liberated amoebulae pass through the bile duct, and reach the gall bladder where they grow into trophozoites and undergo sporulation.

In the case of $L$. ohlmacheri, the circumstances are similar to those of 
C. protei, but differ from the latter forms. Ohlmacher's view is untenable because myxosporidian spores have no power of locomotion and have never been seen or been made to germinate in water outside of the host.

As previously stated, a series of experiments was carried out to discover the way in which infection occurs. An emulsion of fresh spores in physiological solution was prepared. Small pieces of a sterilized cork, made porous by means of a fine needle, were immersed in the emulsion, and introduced into the oesophagus of several specimens of $R$. pipiens. Small pieces of infected kidneys were also fed in a similar manner. At various intervals of time, the animals were dissected. The cork was found in the pylorus even after 48 hours, and in two cases it was seen to have reached the large intestine. The corks, after being taken out, were cut into smaller pieces on many slides and studied. Four intestines with the introduced corks were fixed and sectioned.

Hanging drop preparations were made by mixing fresh spores with the fluids taken from various parts of the digestive tract. Further changes than the extrusion of polar filaments and occasional separation of the shell-valves were noticed only in the preparations with the gastric fluid with or without bile or fluid from the duodenum. In these preparations which have been absolutely free from mechanical pressure, the amoebulae were frequently noticed making their way through the opening of the spore membrane. Similar changes were noticed in the smears of corks taken from the pylorus. From these experiments, we may conclude that the amoebula emerges in the pylorus or duodenum of the new host.

It may seem probable that the liberated amoebulae pass through the alimentary canal into the cloaca where the ureters open, as was thought by Davis in S. dimorpha, and make their way up the ureters and further into the uriniferous tubule of the kidney. However, this supposition does not seem to hold, as the young stages only occur in or near the Malpighian bodies.

I therefore concur with Joseph's opinion that the liberated amoebulae penetrate through the wall of the digestive tract, appear in the coelomic fluid, and finally reach the nephrostome through which they further make their way into the lumen of the uriniferous tubule of the host's kidney. Judging from the conditions observed in sections of infected kidney, this seems to be the most common way for amoebulae to reach their final seat of infection. Frequently the space between Bowman's capsule and the glomerulus of the Malpighian body is greatly enlarged, and filled with young as well as sporulating trophozoites, while the uriniferous tubule originating from this body, contains no parasites. This may be due to the amoebulae which have entered the blood stream and which, after reaching the capillary in the glomerulus, have traversed its wall and become free in the said space where active multiplication takes place.

The mature spores pass down the uriniferous tubules and ureters, and escape outward through the anus. When they are swallowed by a new host, the fresh infection follows. 


\section{THE RELATION BETWEEN THE HOST AND THE MYXOSPORIDIAN.}

$L$. ohlmacheri has been observed in the following three North American batrachian host species: B. lentiginosus (Illinois, after Ohlmacher and Whinery), $R$. clamitans (New York, after Kudo) and $R$. pipiens (locality unknown, after Kudo).

As was mentioned on p. 121, Thélohan gave no description of his L. ranae which would permit of two species of Leptotheca similar in habitat being differentiated. $L$. ranae is probably identical with $L$. ohlmacheri because some species of Ranidae such as $R$. temporaria and $R$. agilis, occur both in America and Europe. Ohlmacher kept his infected toad with two dozen frogs ${ }^{1}$, which he did not examine. In my opinion these frogs were also infected by the Myxosporidian, and acted as a source of infection for Bufo lentiginosus. I further think that if examination of various species of frogs from different localities is carried out, the Protozoon may be found to be far less specific and more cosmopolitan.

Fourteen specimens of $R$. clamitans were examined from July 31 to September 5, 1920. They measured from 3 to $10 \mathrm{~cm}$. in length. Of these, eight were males and six females. The examination showed that three males and three females were infected. Twenty-four specimens of $\boldsymbol{R}$. pipiens were examined between November 12 and December 6, 1920. They measured from 8 to $10 \mathrm{~cm}$. long. Of these fifteen were males and the remaining nine females. The examination showed that seven males and three females were infected. The percentage of infection in the two host species $R$. clamitans and $R$. pipiens are 43 and 42 respectively.

Although $R$. pipiens were almost of similar size, a great variation in the size of $\boldsymbol{R}$. clamitans was noticed. One individual, which was only $3 \mathrm{~cm}$. long, had both its kidneys heavily infected, young as well as sporulating trophozoites being present in large numbers. On the other hand, three individuals, $10 \mathrm{~cm}$. in length, were found to be free from the infection. The infected animals varied from 5 to $9 \mathrm{~cm}$. in length. This probably indicates that the infection occurs at any stage of the development of the host. Further, the infection was recognized only in five specimens collected from a short stretch of creek "a" between August 3 and 17. The other individual mentioned above was obtained on August 25 from creek "b." where two other uninfected larger specimens were also collected.

Concerning the effect of the infection upon the host animal, I have not seen any serious pathological change which might cause the death of the host. As to the possible effect of the parasites upon the toad, Ohlmacher made the following statement:

As to the pathogenic rôle of the Myxosporidia in this case, there can scarcely be a doubt but that they were the direct factors in the production of the pathological changes leading to the death of the host. In fact, the tubules of both kidneys were filled with the parasites;

1 No specific name is given. 
and it is evident that the mere mechanical effect of this foreign material in the tubules must have led to an obstruction of the secretory functions of the organ, and as a remote result, to the ascites and general oedema. Undoubtedly, the presence of large numbers of bacteria in the already overburdened kidney was potent in hastening the fatal termination; but these vegetable microorganisms must be regarded as the elements of a secondary infection. It is not difficult to conceive that the diseased kidney, with its damaged secretory funetion, would furnish an inviting focus for bacterial invasion; and particularly since the route from the exterior is such a direct one in these animals in which the urinary secretions empty into a cloaca.

Whinery (1913) collected "about a dozen" B. lentiginosus, and kept them in a sink. The toads died in confinement within three weeks. Two males and five females were examined, one male and four females being found to be infected. About the condition of the toads, he remarked as follows:

Before death no external change in appearance of the animals was noticed, with the exception of a distension of the abdomen in some cases. Opening the abdominal wall, some increase in the amount of peritoneal fluid was usually noticed, but never a large amount in the toad examined and described by Dr Ohlmacher. The abdominal viscera showed signs of congestion. The kidneys were enlarged and in a congested state. The intestines were usually distended with gas.

In $R$. clamitans and $R$. pipiens infected by $L$. ohlmacheri, I could not recognize any difference either in external appearance or in activity between uninfected and infected animals. No marked difference in the quantity of coelomic fluid in healthy and infected animals was noticed. The internal organs of different individuals were carefully compared, but no definite data could be obtained regarding the possible effect of the infection upon the organs.

The kidneys of infected frogs seemed to be slightly larger than those of the uninfected, and they were usually greatly congested. In the case of $R$. clamitans, this could not be explained merely as a result of the Myxosporidian infection, because trypanosomes were found in almost every host in far greater number in the blood vessels of the kidneys than in those of other organs. The congested condition of the kidneys observed in some of the infected $R$. pipiens was, however, probably due to the Myxosporidian infection, because few trypanosomes were present in this species.

The examination of sections revealed but little disturbance in the secretory function of the kidney, since the parasites do not seem to invade the tissue, but simply lie in the lumina of the uriniferous tubules probably absorbing the fluid waste matter secreted by the host cells. A parasite will be tolerated for a long time provided that it does not greatly harm its host.

\section{SUMMARY.}

1. Rana clamitans of New York and $R$. pipiens from the middle part of the United States, were found to be infected by a Myxosporidian, apparently identical with Leptotheca ohlmacheri (Gurley) Labbé, found by Ohlmacher in the kidney of Bufo lentiginosus. 
2. The Myxosporidian was found only in the space between Bowman's capsule and the glomerulus of the Malpighian body and in the uriniferous tubules of the kidneys of the host, no other organ being infected.

3 . The mature spore contains two independent uninucleate sporoplasms which fuse into one prior to the germination in the posterior region of the stomach or duodenum of a new host.

4. The germination of the spore was observed in hanging drop preparations with the digestive fluid.

5. The youngest stage found in the lumen of the tubule of the kidney, was the uninucleate form.

6. The trophozoites multiply actively by a process of gemmation and probably also by a schizogony of the uninucleate forms.

7. The trophozoites are, as a rule, disporous and the spores develop independently of each other.

8. The vegetative nucleus persists throughout the entire trophic life of the individual.

9. The Myxosporidian does not exercise any fatal effect upon the host.

10. Infection takes place through the mouth. The liberated binucleate amoebulae probably penetrate through the wall of the small intestine, reach the coelom and are carried to the uriniferous tubules through the nephrostomes or blood vessels.

\section{REFERENCES.}

Averbach, M. (1910). Die Cnidosporidien. Leipzig.

Awerinzew, S. (1909). Studien über parasitischen Protozoen. I. Die Sporenbildung bei Ceratomyxa drepanopsettae mihi. Arch. Protist. xIv. 74-112, Pls. VII-VIII.

Davis, H. S. (1916). The structure and development of a myxosporidian parasite of the squeteague, Cynoscion regalis. Journ. Morph. xxvir. 333-377, PIs. I-VII.

- (1917). The Myxosporidia of the Beaufort region. A systematic and biologie study. Bull. Bureau of Fisheries, xxxv. 203-243, Pls. XVI-XXIV.

Debatsiedx, P. (1918). Notes sur le Myxidium lieberkiühni Bütschli. La Cellule, xxx. 281290 , PI. I.

Erdmann, R. (1912). Zur Lebensgeschichte des Chloromyxum leydigi, ciner mictosporeen Myxosporidie. Teil I. Arch. Protist. xxIv. 149-162, Pls. XII-XIV.

- (1917). Chloromyxum leydigi und seine Bezichung zu anderen Myxosporidien. Teil II. Arch. Protist. xxxvII. 276-326, Pls. XVII-XX. 17 Text-figs.

- $(1917 a)$. New facts and views concerning the occurrence of a sexual process in the myxosporidian life eycle. Amer. Natural. LI. 719-739.

GEorgévitch, J. (1916). Note sur les Myxosporidies des poissons de la baie de Villefranche et de Monaco. Bull. l'Inst. Océanogr. No. 322. 5 Text-figs.

- (1917). Recherches sur le développement de Ceratomyxa heramardi Georgév. Arch. zool. exper. LVI. 375-399, Pls. XI-XIII.

- (1917a). Esquisses protistologiques. III. Sur le eycle évolutif de Ceratonyxa coris Georgévitch. Bull. l'Inst. Océanogr. No. 328. 50 Text-figs.

Gurley, R. R. (1894). The Myxosporidia or psorosperms of fishes, and the epidemies produced by them. Report U.S. Fish Comm. v, 65-304, Pls. I-XLVII.

Joseph, H. (1907). Chloromyxum protei n.sp., ein in der Niere des Grottenolmes parasitierendes Myxosporidium. Arch. Protist. viII. 398-412, PIs. XVI-XVII. 
Kudo, R. (1916). Contributions to the study of parasitic Protozoa. I. On the structure and life history of Nosema bomoycis Nägeli. Bull. Imer. Sericult. Exper. Stat. I. 31-51, Pls. I-II.

(1917). Contributions, ete. II. Myxobolus toyamai n.sp., a new Myxosporidian parasite of Cyprinus carpio L. Journ. Parasit. IIr. 163-170, Pls. I-II.

(1920). On the structure of some Microsporidian spores. Journ. Parasit. vi. 178-182.

11 Text-figs.

- (1920a). Studies on Myxosporidia. A synopsis of genera and species of Myxosporidia. Illinois Biol. Monogr. v. 239-503, Pls. I-XXV. 2 Text-figs.

(1920b). Notes on Nosema apis Zander. Journ. Parasit. vir. 85-90. 14 Text-figs.

(1921). Studies on Microsporidia with special reference to those parasitic in mosquitoes. Journ. Morph. xxxv. 153-193, Pls. I-V. 1 Text-fig.

(192la). On the nature of structures characteristic of Cnidosporidian spores. Trans. Amer. Micros. Soc. xL. 59-74.

- $(1921 b)$. On some Protozoa parasitic in fresh-water fishes of New York. Journ. Parasit. viI. 166-174. 25 Text-figs.

- (1922). On the effect of some fixatives upon Myxosporidian spores. Trans. Amer. Micros. Soc. Xu. 4 Text-figs.

Labbé, A. (1899). Sporozoa. Berlin.

Ohlmacher, A. P. (1893). Myxosporidia in the common toad with preliminary observations on two chromophile substances in their spores. Journ. Amer. Med. Assoc. xx. 561-567, PI. I.

St empeld, W. (1919). Untersuchungen über Leptotheca coris n.sp. und das in dieser schmarotzende Nosema marionis. Arch. Prolist. XL. 113-157, Pls. V-XII. 1 Text-fig.

Thélohan, P. (1895). Recherehes sur les Myxosporidies. Bull. Sci. France et Belg. xxvi. 100-394, PIs. VII-IX. 5 Text-figs.

Whinery, J. B. (1893). Some additional notes on a Myxosporidian infeetion in the common toad. New York Med. Journ. xviII. 660-662. I Text-fig.

\section{EXPLANATION OF PLATES $X I I I-X X$.}

All the figures, except Figs. 104 to 111 , represent various stages in the development of Leptotheca ohlmacheri. The figures were drawn with the aid of Abbé's drawing apparatus at the level of the base of the microscope, with the combinations of Zeiss' compensation oculars 8 and 12 and homogeneous oil immersion objective $2 \mathrm{~mm}$., thus obtaining magnifications of about 1500 and 2350 diameters respectively. Figs. 1 to 86,88 to 95 and 101 to 111 , were magnified 2350 , and the rest 1500 diameters. The abbreviations used in the explanation are as follows: $B$., Bouin fixation; $C$., from the kidneys of Rana clamitans; $D$., staining with Delatield's haematoxylin; $F$., 4 per cent. formol fixation; $G$., staining with Giemsa's solution, followed by acetone dehydration and mounted in cedar oil; $H$., staining with Heidenhain's iron haematoxylin; $P$., from the kidneys of Rana pipiens; S., section preparations; Sa., Schaudinn's fixation; Sm., smear preparations; Tcs., thickly made smears; I'ns., thin smears.

\section{PLATE XIII.}

Fig. 1. A spore treated for 30 minutes with the gastric fluid of the frog in a hanging drop preparation, showing the fusion of the two sporoplasms. P.Tns.Sa.G.

Figs. 2, 3. Two views of a spore which was kept for 2 hours in the stomach fluid of the frog animal $(P)$, drawn from a fresh hanging drop preparation. The two sporoplasms fused into one mass and are seen pressing the polar capsules against the anterior margin of the spore membrane. $P$.

Fig. 4. Another spore treated like the last one for 6 hours, showing the binucleate amoebula emerging through the opening made by the separation of the shell-valves. The empty polar capsules lost their spherical form under the pressure of the amoebula. The greater portion of the filaments are not shown. P.Tns.Sa.G. 
Fig. 5. A spore treated for 16 hours with a weak pepsin hydrochloric acid in a hanging drop preparation. The amoebula is seen eseaping through the opening. The emergence did not take place further than this condition although it was observed for 40 minutes. $P$.

Fig. 6. A spore under a similar treatment to those shown in Figs. 2-6, for 6 hours. P.T'ns.B.H.

Fig. 7. A later stage than the one shown in Fig. 4. P.Tns.Sa.G.

Fig. 8. A liberated amoebula lying beside the empty spore membrane, after being treated with the gastric fluid for 16 hours. P.Tns.Sa.H.

Fig. 9. An amoebula observed in a hanging drop preparation of spores and stomach fluid after 22 hours. The fusion of the two nuclei is seen taking place. P.Sm.Sa.G.

Figs. 10, 11. Fresh amoebulae from the same preparation which contained the amoebula shown in Fig. 8. $P$.

Fig. 12. An amoebula whose nuclei are undergoing fusion. P.Tns.Su.G.

Figs. 13-16. Four stages of sehizogony in the tubules of kidney. P.S.Su.G.

Figs. 17, 18. Young trophozoites from the uriniferous tubules of the frog's kidney. P.S.Sa.G.

Fig. 19. A young trophozoite. P.S.Sa.G.

Fig. 20. A young trophozoite. P.Tns.B.D.

Fig. 21. A fully grown uninucleate trophozoite. P.Tns.Su.G.

Figs. 22-25. Stages in nuclear division of uninucleate forms. P.Tns.Sa.G.

\section{PLATE XIV.}

Fig. 26. A binucleate trophozoite, with its vegetative and the dividing generative nucleus, attached to the epithelial cell of the tubule of the frog's kidncy. C.S.F.D.

Figs. 27, 28. Trophozoites, one of the nuclei (the generative nucleus) having just completed its division producing two generative nuclei. P.Tns.Sa.G.

Fig. 29. Two views of a trinucleate trophozoite attached to the epithelial cells of the tubule of the frog's kidney. The generative nucleus has just completed its division C.S.Sa.D.

Fig. 30. A typical trinucleate trophozoite. C.S.Sa.D.

Fig. 31. A trinucleate trophozoite. P.Tns.Sa.G.

Fig. 32. A trinucleate trophozoite. P.Tns.B.H.

Fig. 33. A trinucleate trophozoite, the vegetative nucleus undergoing further division. P.Tns.Sa.D.

Fig. 34. A tetranucleate trophozoite. P.Tns.Sa.D.

Fig. 35. A similar stage. The nucleus on the right of the vegetative nucleus is surrounded by a clear space, and dividing to form a gemma. P.Tns.Sa.G.

Fig. 36. A similar stage. P.Tns.Sa.D.

Fig. 37. A trophozoite with a gemma. Besides the vegetative nucleus which is seen below and two generative nuclei on the left, an island of cytoplasm with similar nuclei, a gemma, is observable. C.Tns.Sa.G.

Fig. 38. A trophozoite with a gemma at the left half, the cytoplasm being spread out in an extremely thinly made smear. In the right half, six generative nuclei beginning to form a spore, below which a large vegetative nucleus is noticeable. C.Tns.Sa.G.

\section{PLATE XV.}

Fig. 39. A more developed trophozoite with a fully grown gemma. P.T'ns.Sa.G.

Fig. 40. A trophozoite with a fully grown gemma. P.Ins.Sa.G.

Figs. 41-43. Liberated gemmae, each with a vegetative nucleus and two generative nuclei.

Fig. 41, C.S.Sa.G.; Fig. 42, P.Tcs.Sa.D.; Fig. 43, P.Tcs.Sa.D.

Fig. 44. A trophozoite showing the dividing generative nuclei. P.Tns.Sa.G.

Figs. 45-47. Trophozoites, each with a vegetative nucleus and four gencrative nuclei. Fig. 45, P.Tns.Sa.G.; Fig. 46, C.S.Sa.D.; Fig. 47, P.Tcs.Sa.D.

Fig. 48. A trophozoite. The vegetative nucleus and one of the generative nuclei are undergoing division. P.Tcs.Sa.D.

Fig. 49. A trophozoite with a vegetative nucleus and seven generative nuclei, one of which is further dividing. C.S.F.D.

Fig. 50. A trophozoite with a vegetative nucleus and eight generative nuclei. C.S.Sa.H. 


\section{PLATE XVI.}

Fig. 51. A fresh trophozoite with one vegetative nucleus and eight generative nuclei. $P$.

Fig. 52. A trophozoite at a later stage. P.Tns.Sa.G.

Fig. 53. A trophozoite showing a vegetative nucleus and twelve generative nuclei which are arranged in two groups. In each group, two capsulogenous cells, two sporoplasms and two valve cells are seen. C.T'ns.Sa.G.

Fig. ö4. A more advanced stage. C.Tns.Sa.G.

Fig 55 . A fresh trophozoite at an almost similar stage of the development to the last. $P$.

Fig 56. A more developed form. P.Tns.Sa.G.

\section{PLATE XVII.}

Fig. 57. A trophozoite greatly spread out in the smear. C.Sa.G.

Fig. 58. Another trophozoite. C.Tns.Sa.G.

Fig. 59. A trophozoite with two more advanced spores. P.Tns.Sa.G.

Fig. 60. A trophozoite with two spores in which the formation of polar filaments is clearly observable. CTns.Sa.G.

Figs. 61-67. Young spores at various stages of development, the rest of the body of the trophozoites are not shown. C.Tns.Sa.G.

\section{PLATE XVIII.}

Figs. 68-70. More advanced stages in the spore formation. C.Tns.Su.G.

Fig. 71. A section through a trophozoite attached to an epithelial cell of the host tubule. This section showed only one of the spores and the vegetative nucleus. C.S.Sa.H.

Figs. 72, 73. Young spores, one showing the formation of polar filaments. C.S.F.H.

Fig. 74. A young spore. C.S.Sa.H.

Fig. 75. A spore showing foramina for the polar filaments. P.Tns.B.D.

Fig. 76. A spore. C.S.Sa.H.

Figs. 77, 78. Two different end views of a young spore. P.Tns.Sa.G.

Figs. 79, 80. Tangential sections through the anterior region of spores, showing the foramina of polar filaments in front view. C.S.Sa.H.

Fig. 81. A trophozoite with two mature spores of normal size. P.Tns.Sa.H.

Fig. 82. A trophozoite with two deeply stained spores of normal size. P.Tns.Sa.G..

\section{PLATE XIX.}

Fig. 83. A trophozoite with two spores of much smaller size. P.Tns.Sa.G.

Fig. 84. A trophozoite with a normal mature spore and an abnormal spore with three polar capsules under formation. P.Tns.Sa.G.

Fig. 85. A trophozoite with a mature spore of somewhat smaller size and a generative nucleus whose division has so far not taken place. P.Tns.Su.G.

Fig. 86. A monosporous trophozoite. P.Tns.Sa.G.

Fig. 87. A fresh disporous trophozoite. $C$.

Fig. 88. A fresh disporous trophozoite. $P$.

Fig. 89. A fresh disporous trophozoite showing pseudopodia. $P$.

Fig. 90. Optical section of a normal spore in the fresh state. $P$.

Figs. 91-93. Two surface views (Figs. 91, 93) and an optical section (Fig. 92) of an empty spore membrane in the fresh state. $P$.

Figs. 94, 95. Optical section and the upper surface view of a spore of somewhat larger dimensions. $P$.

Figs. 96, 97. Fresh spores. $C$.

\section{PLATE XX.}

Fig. 98. A fresh spore of smaller dimensions. $C$.

Figs. 99, 100. Optical section and a surface view of a spore seen from one side. $G$. 
Fig. 101. An abnormal spore with three polar capsules and shell-valves in the fresh state. $P$ Figs. 102, 103. Spores with extruded polar filaments under the influence of a solution of sodium glycocholate. $P$.

Fig. 104. A red blood corpuscle in the fresh state. $P$.

Figs. 105-108. Leucocytes and "spindle cells" in the fresh state. $P$.

Figs. 109, 110. Mononucleate leucocytes, P.Tns.Sa.G.

Fig. 111. A trinucleate leucocyte. P.Tns.Sa.G. 

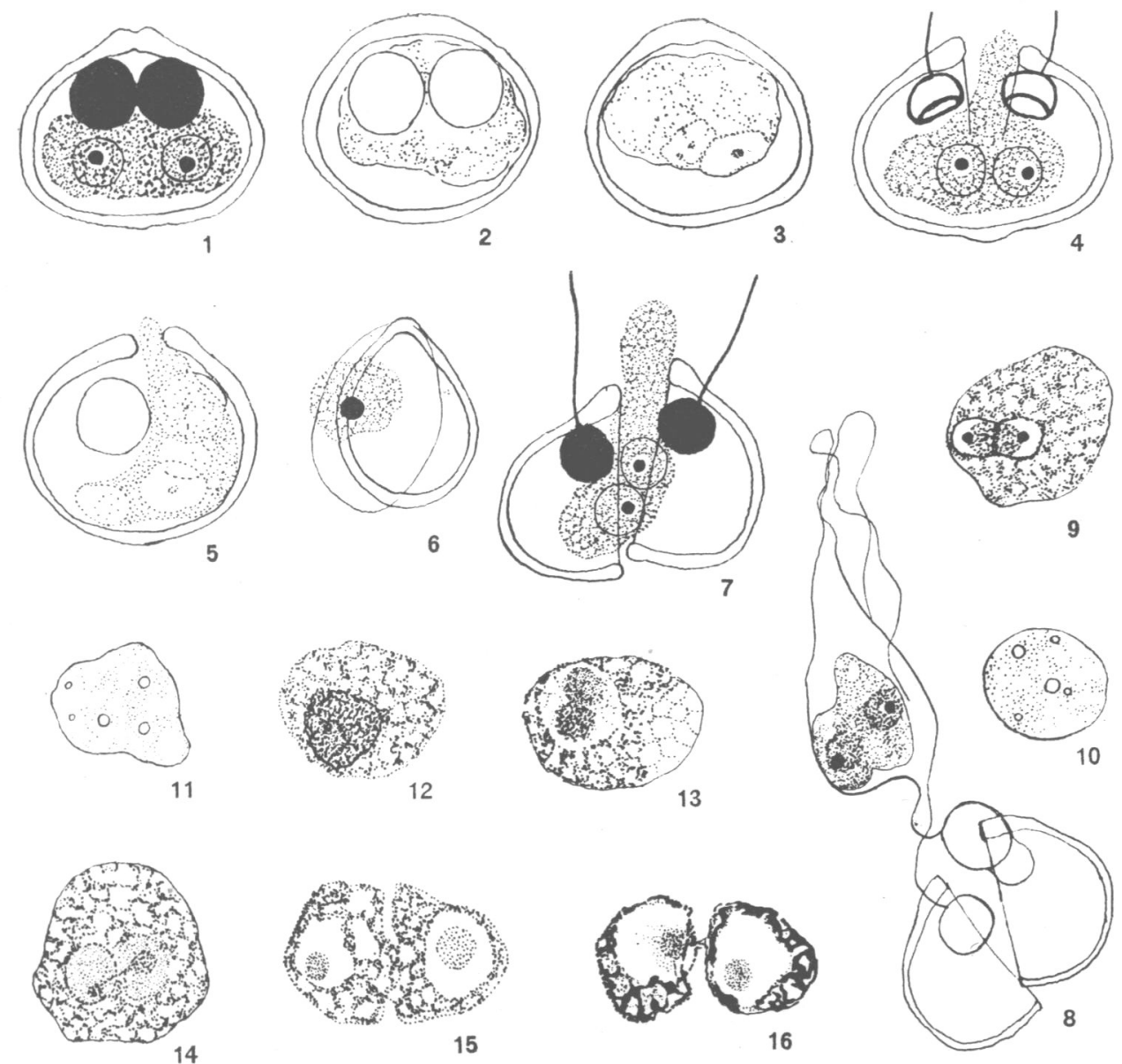

15
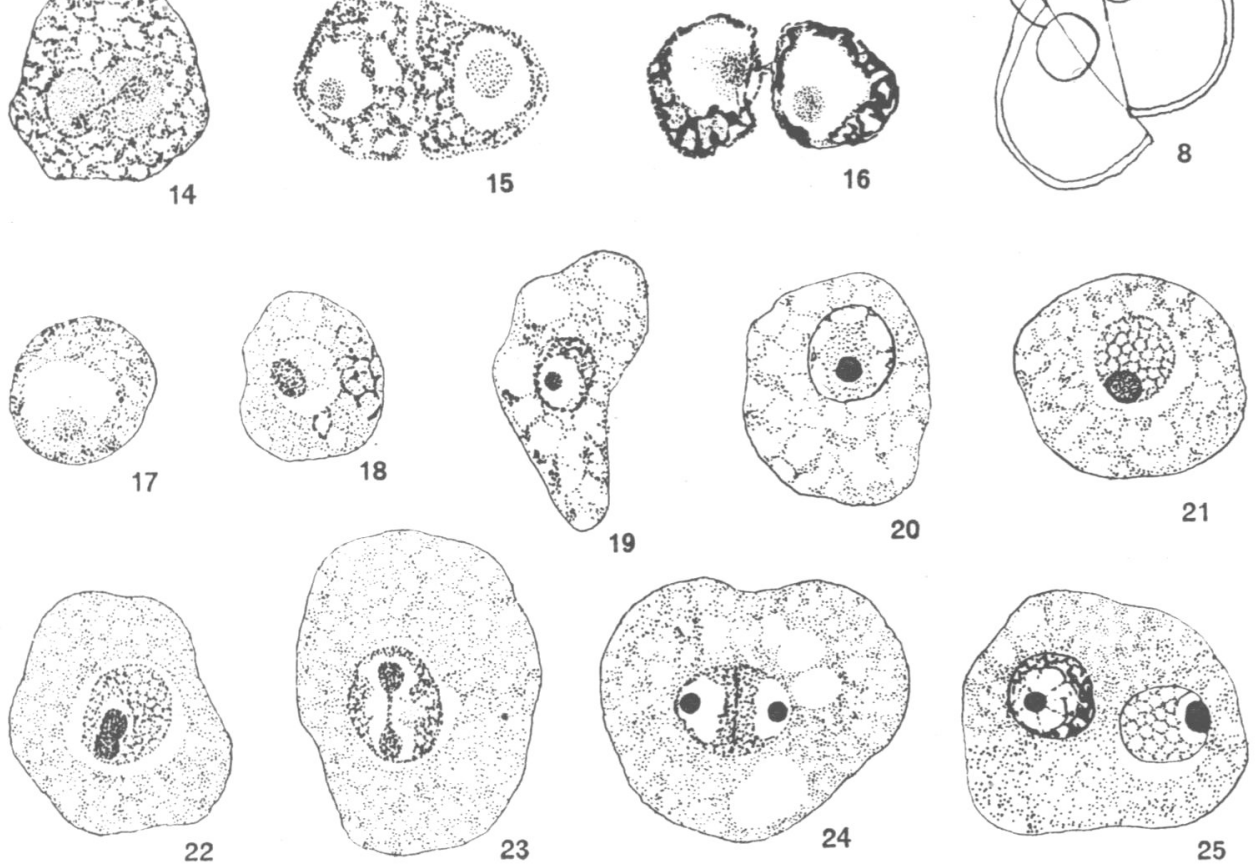

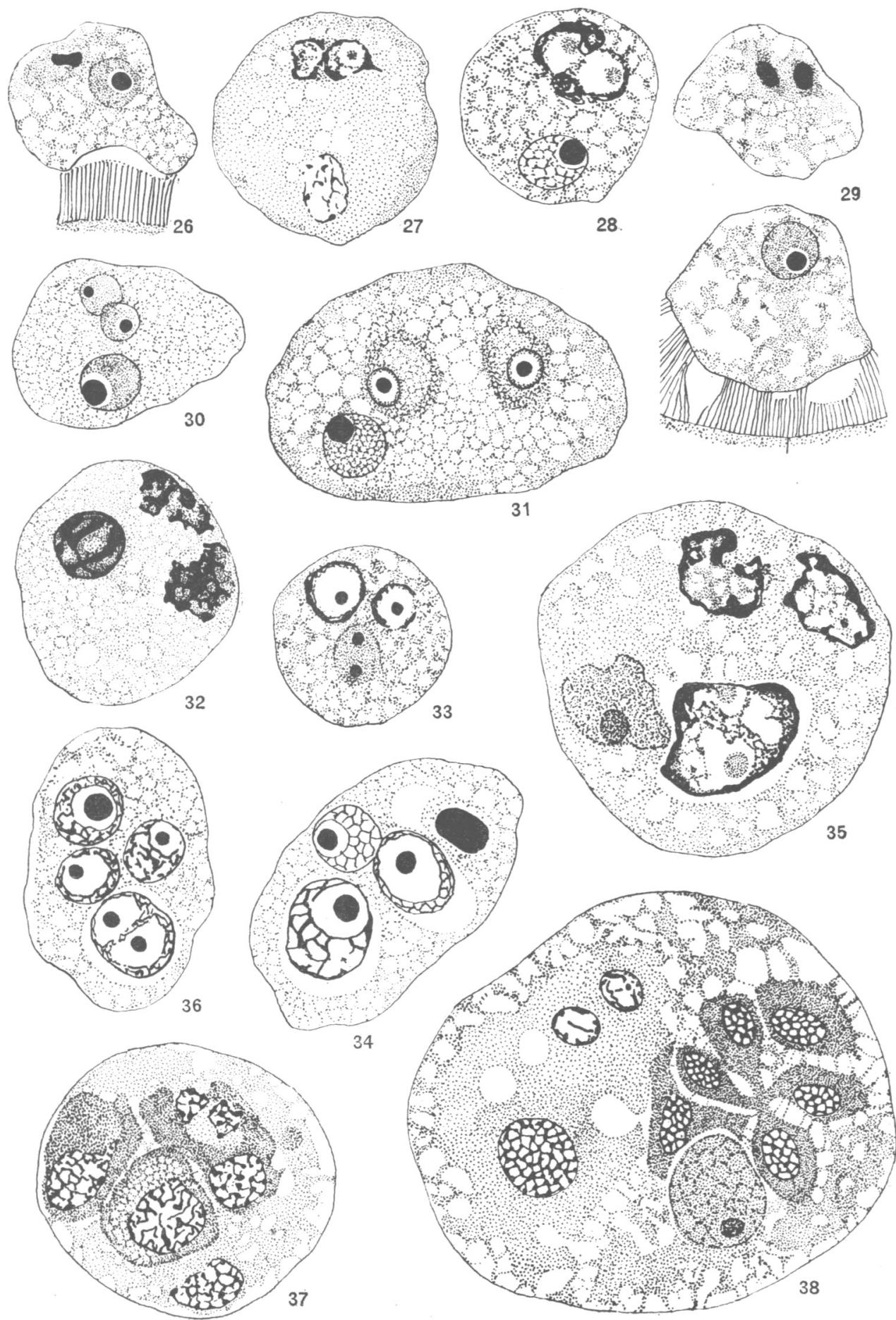

34

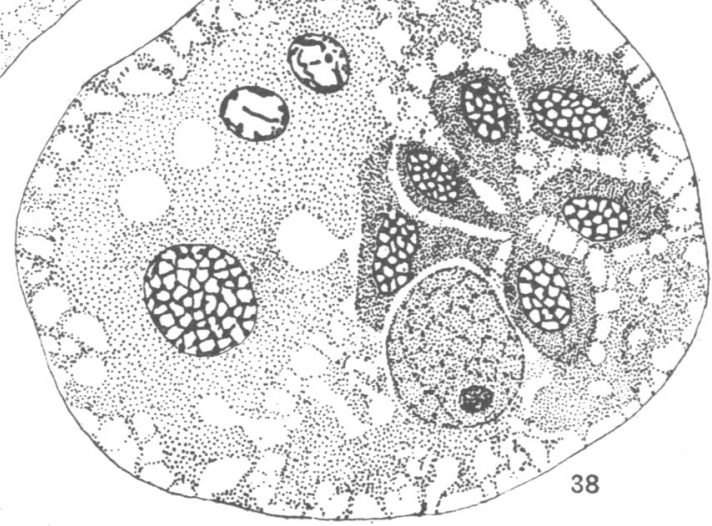



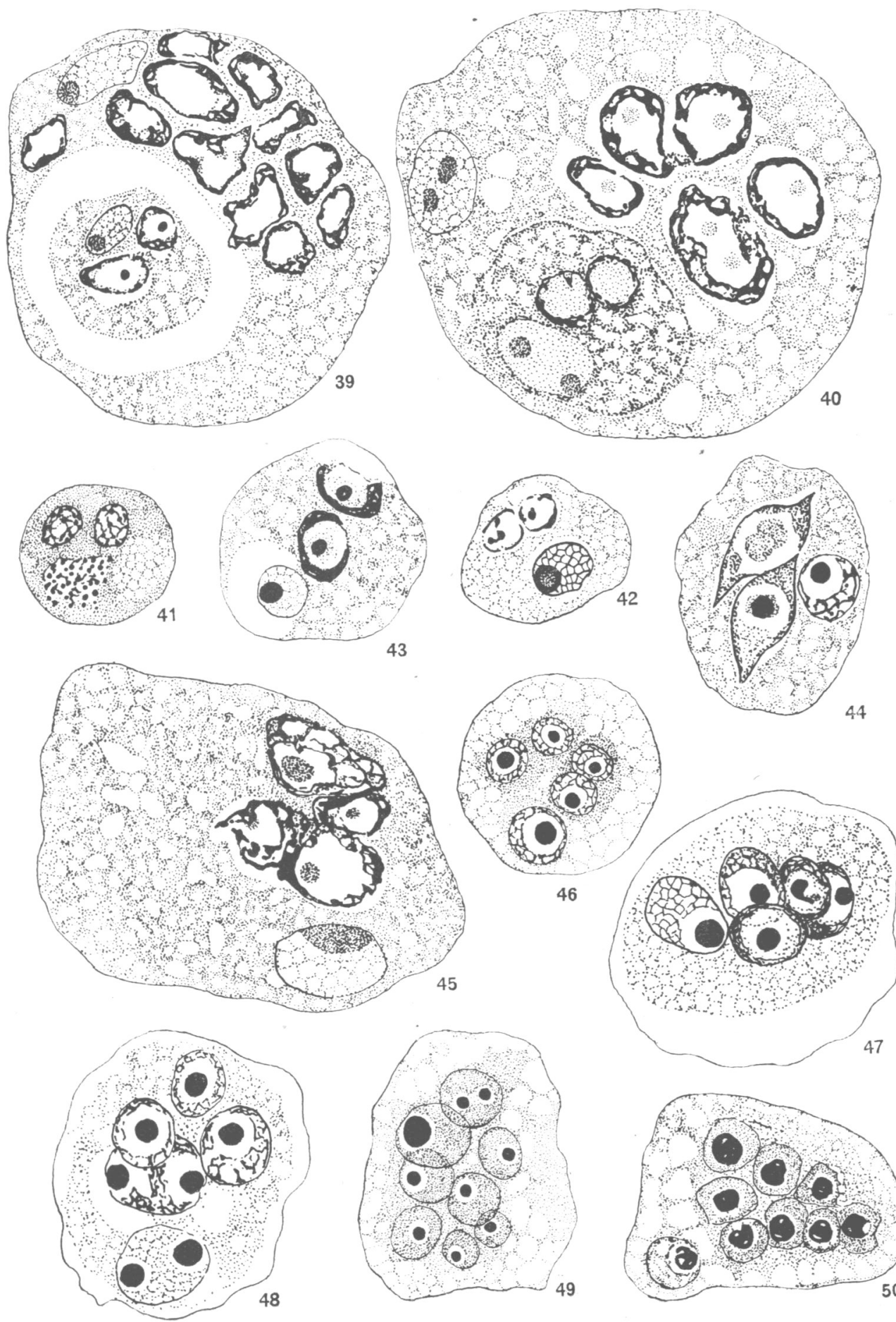

43
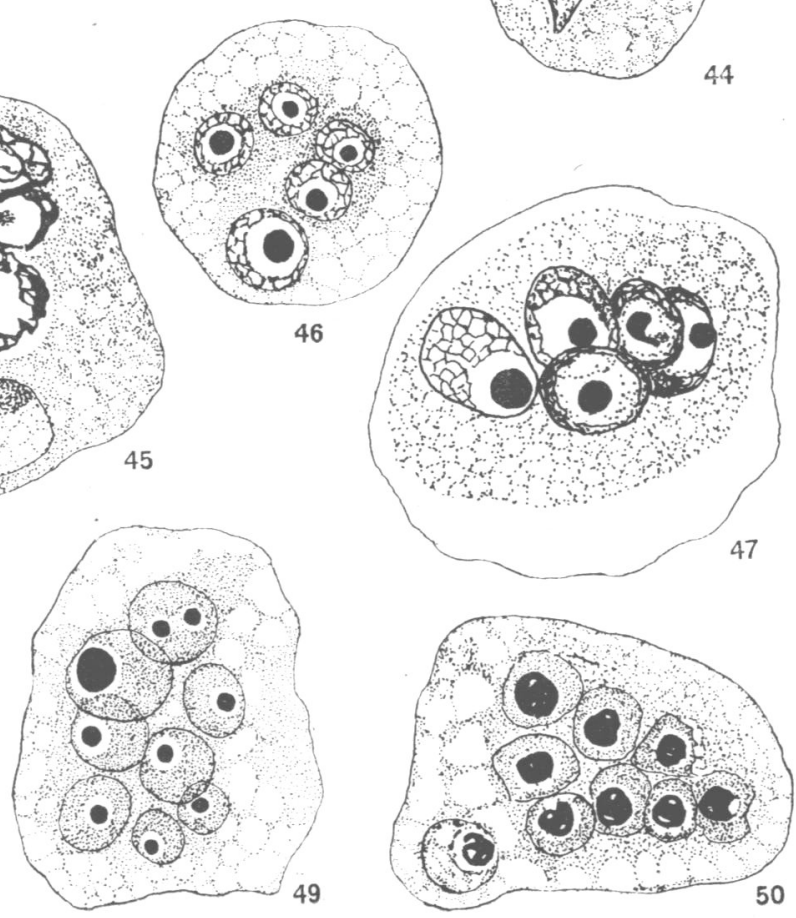

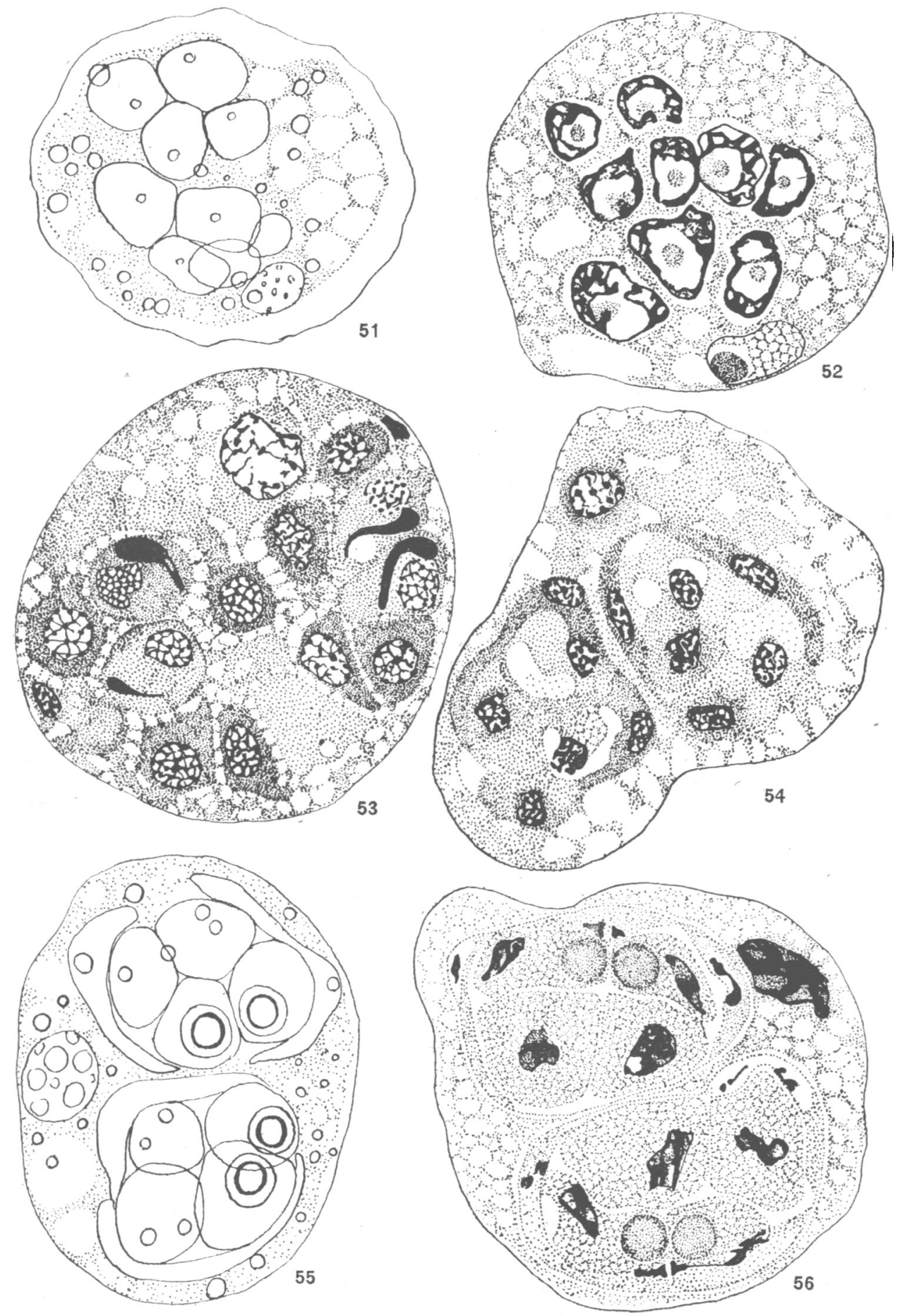


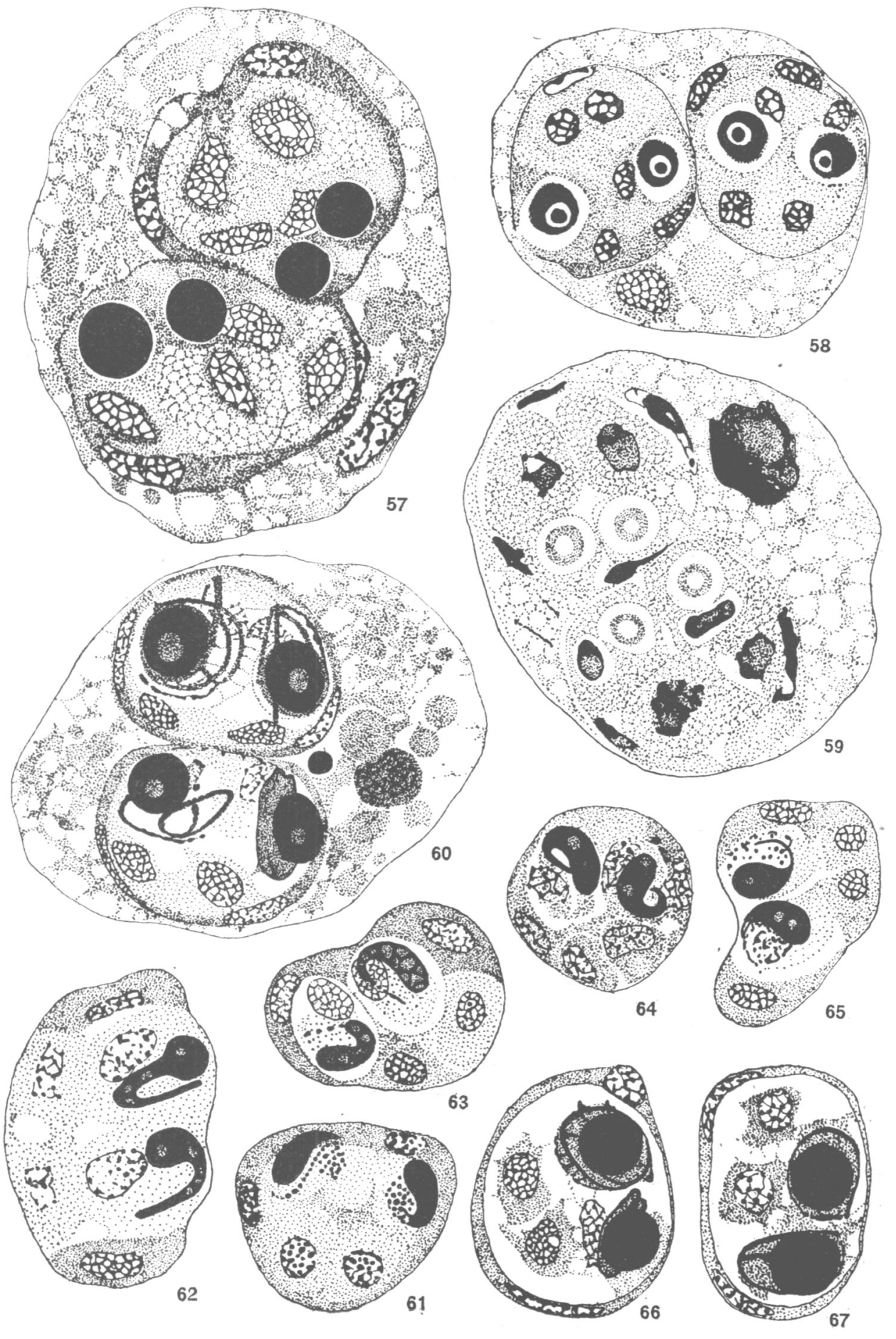



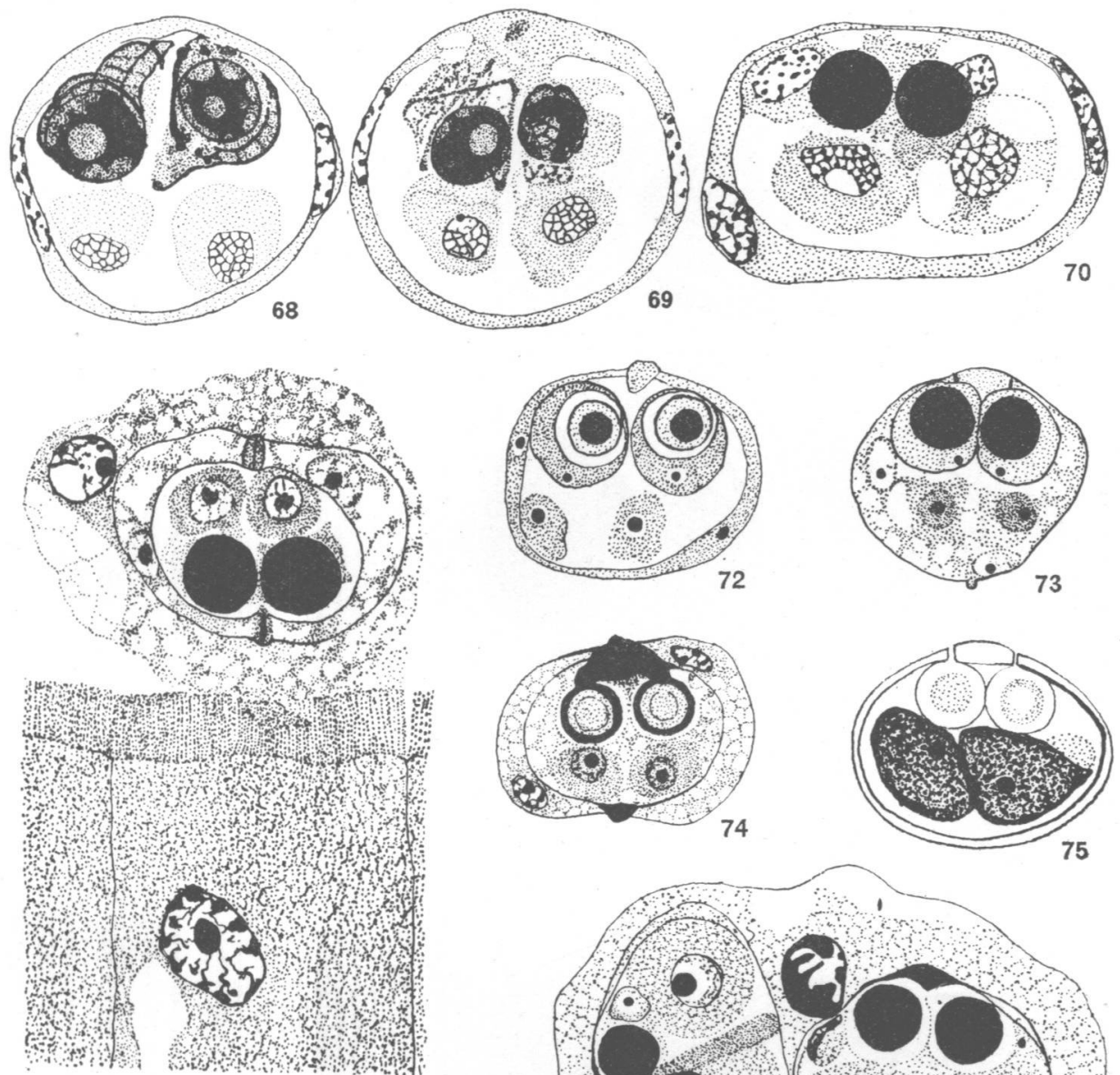

71
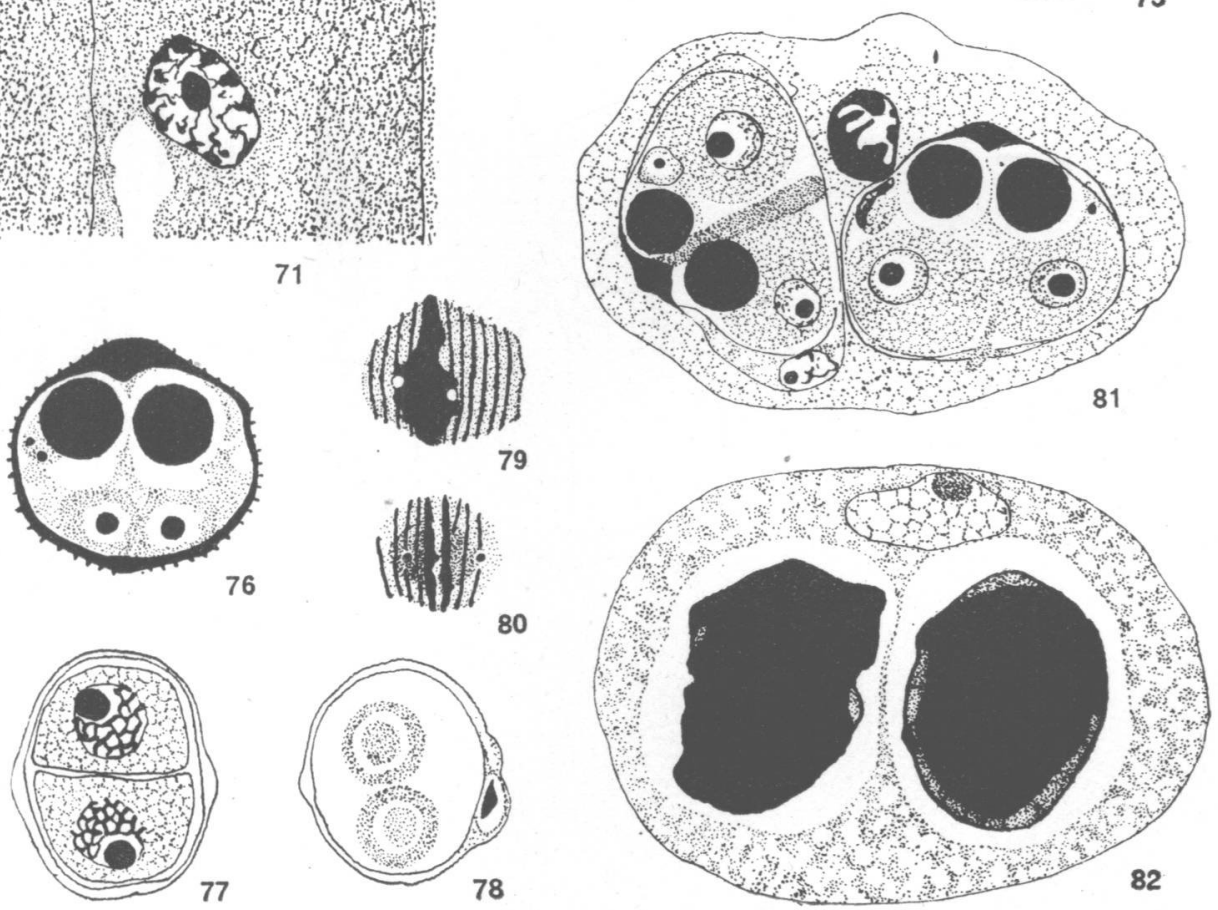

R. Kudo del. 

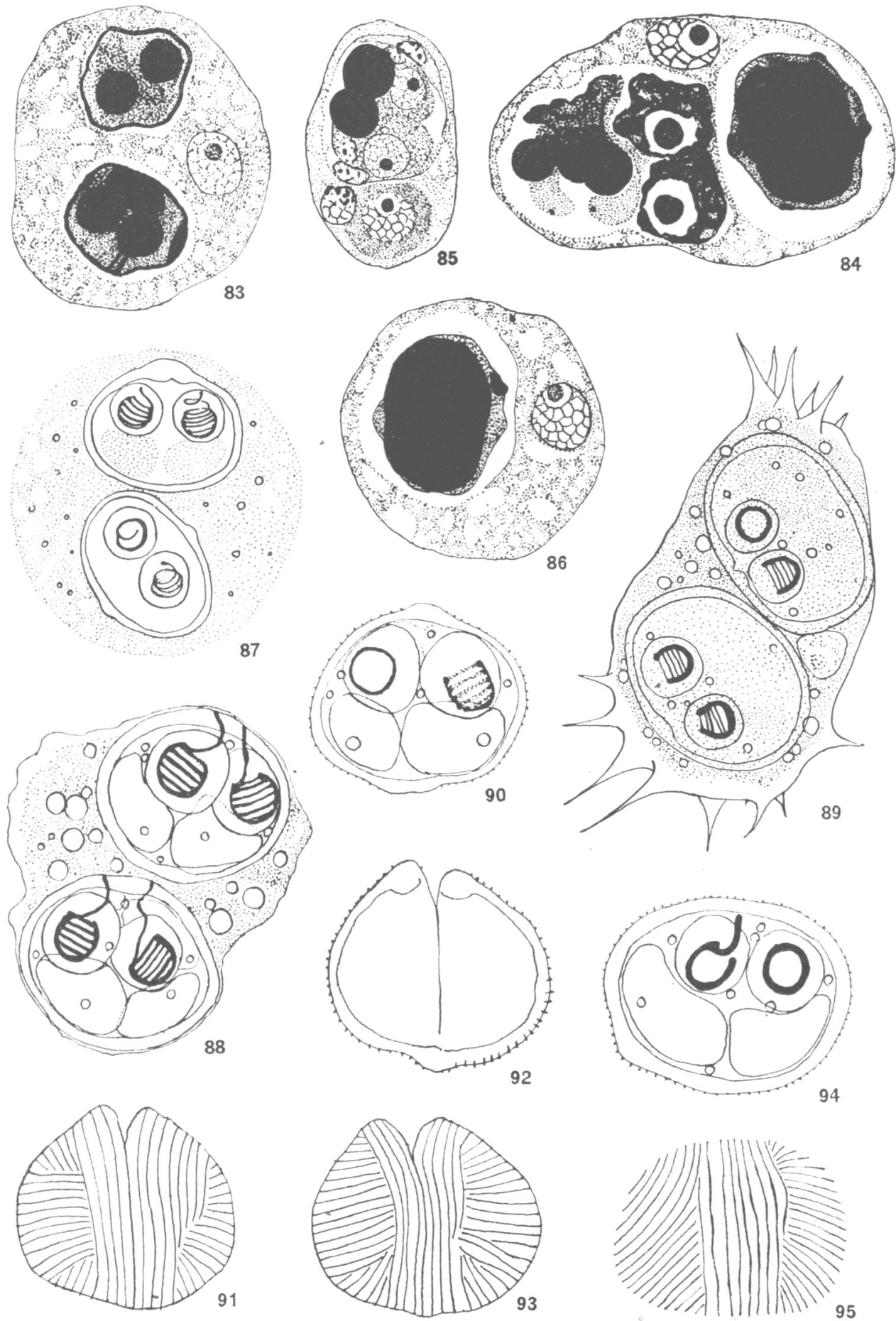

R. Kudo del.

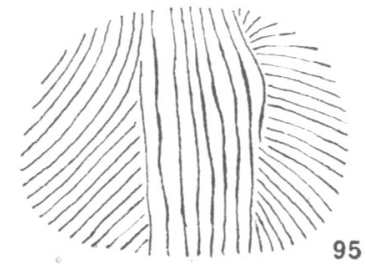


PARASITOLOGY, VOL. XIV. NOS. 3 AND 4

PLATE XX
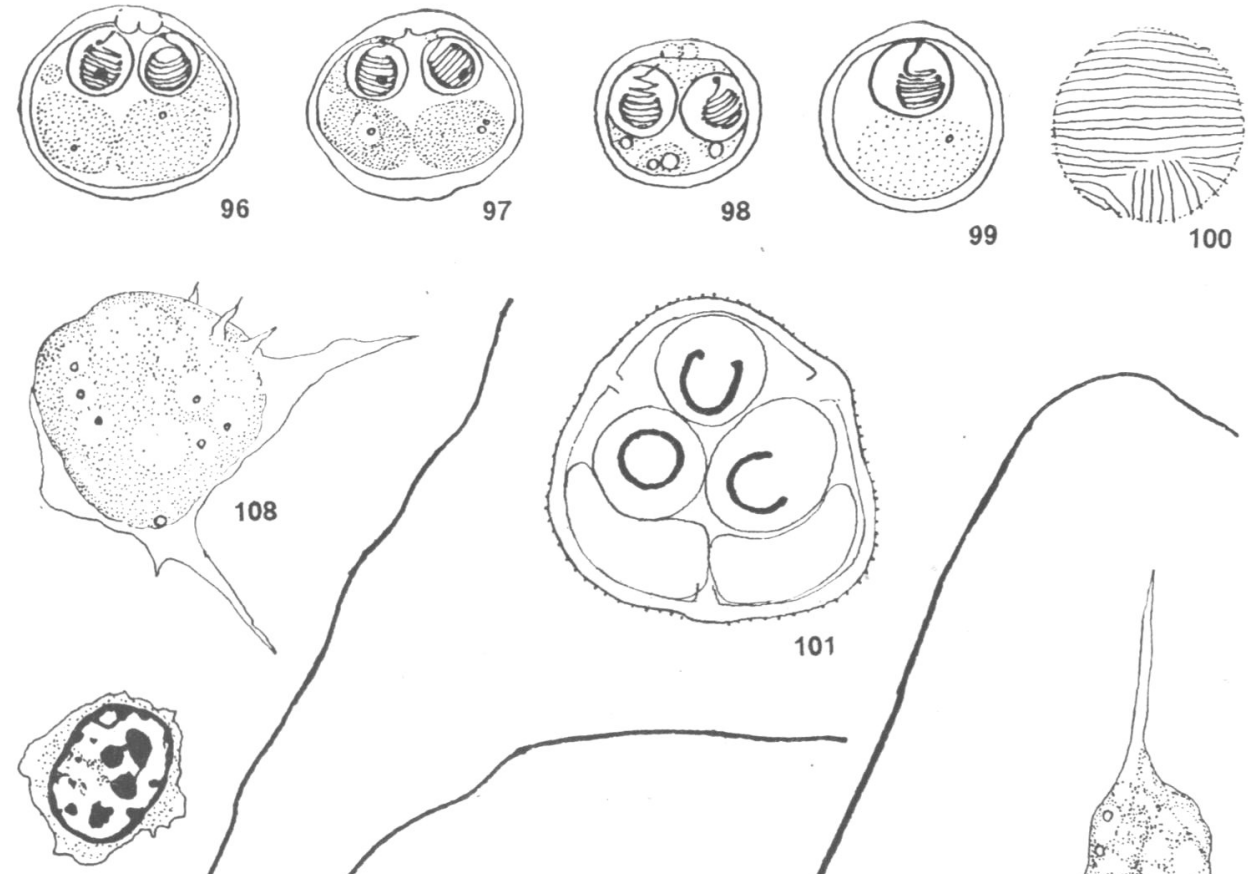

99

100
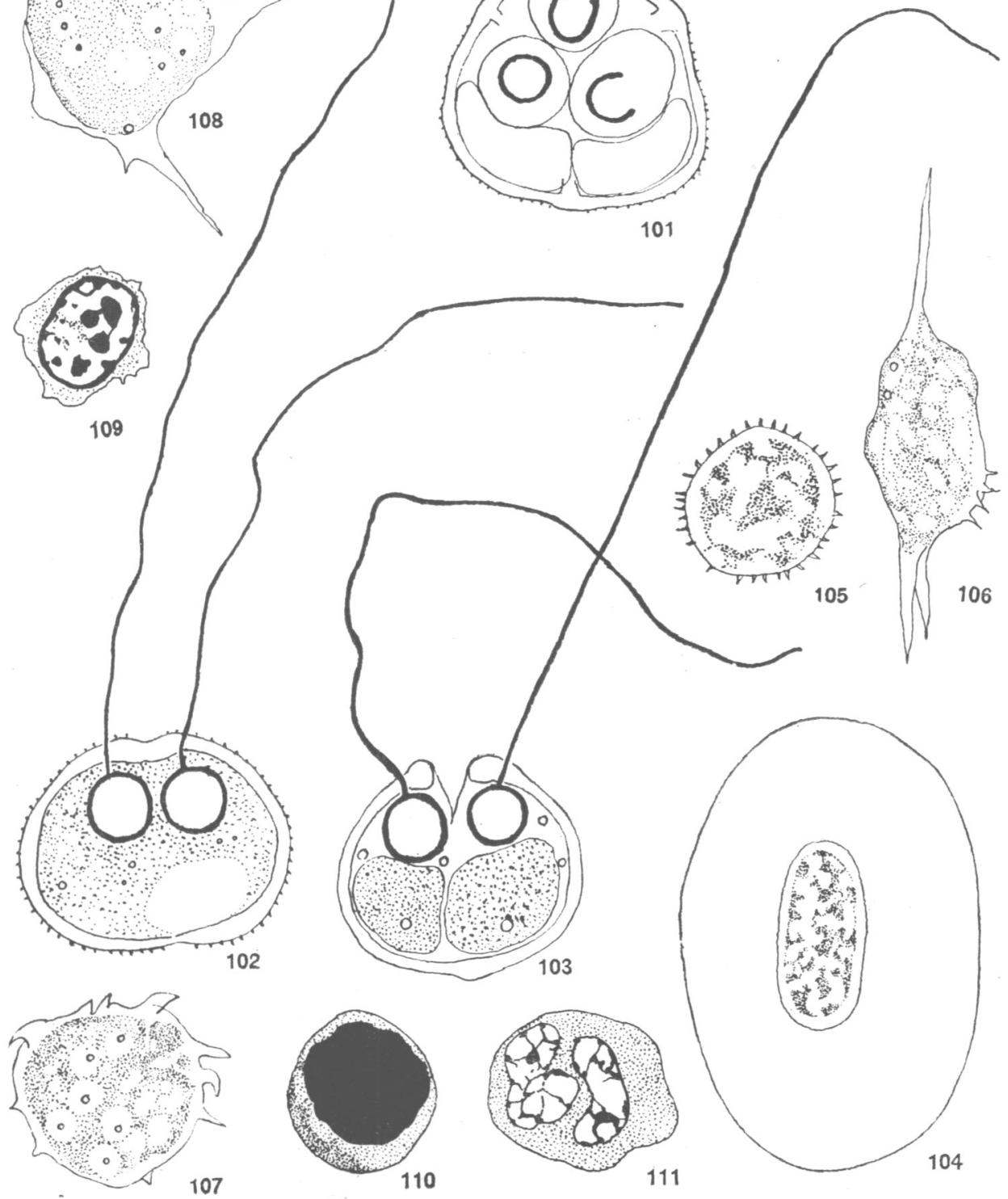

R. Kudo del. 